\title{
LLNL-TR-573693
}

LAWRENCE LIVERMORE N A TIONAL LABORATORY
Wipe Sampling Collection Efficiencies and Holding Time Studies

R. Leif, C. Koester, J. Gruidl, C. Koester

August 14, 2012 
This document was prepared as an account of work sponsored by an agency of the United States government. Neither the United States government nor Lawrence Livermore National Security, LLC, nor any of their employees makes any warranty, expressed or implied, or assumes any legal liability or responsibility for the accuracy, completeness, or usefulness of any information, apparatus, product, or process disclosed, or represents that its use would not infringe privately owned rights. Reference herein to any specific commercial product, process, or service by trade name, trademark, manufacturer, or otherwise does not necessarily constitute or imply its endorsement, recommendation, or favoring by the United States government or Lawrence Livermore National Security, LLC. The views and opinions of authors expressed herein do not necessarily state or reflect those of the United States government or Lawrence Livermore National Security, LLC, and shall not be used for advertising or product endorsement purposes.

This work performed under the auspices of the U.S. Department of Energy by Lawrence Livermore National Laboratory under Contract DE-AC52-07NA27344. 


\section{Wipe Sampling Collection Efficiencies and Holding Time Studies}

For EPA under IAG \#DW89922616-01-0

\section{LLNL-TR-573693}

Roald Leif, Carolyn Koester, Jeremiah Gruidl, Heather Mulcahy

Revision 2

June 27, 2012 


\section{Disclaimer}

This document was prepared as an account of work sponsored by an agency of the United States government. Neither the United States government nor Lawrence Livermore National Security, LLC, nor any of their employees makes any warranty, expressed or implied, or assumes any legal liability or responsibility for the accuracy, completeness, or usefulness of any information, apparatus, product, or process disclosed, or represents that its use would not infringe privately owned rights. Reference herein to any specific commercial product, process, or service by trade name, trademark, manufacturer, or otherwise does not necessarily constitute or imply its endorsement, recommendation, or favoring by the United States government or Lawrence Livermore National Security, LLC. The views and opinions of authors expressed herein do not necessarily state or reflect those of the United States government or Lawrence Livermore National Security, LLC, and shall not be used for advertising or product endorsement purposes.

\section{Auspices Statement}

This work performed under the auspices of the U.S. Department of Energy by Lawrence Livermore National Laboratory under Contract DE-AC52-07NA27344. 


\section{Acknowledgements}

The authors wish to acknowledge the support of all those who helped plan and prepare this report. The authors thank National Homeland Security Research Center (NHSRC) of the U.S. Environmental Protection Agency for funding this work and Romy Lee and Matthew Magnuson of this organization for helpful conversations and contributions. We also thank Larry Zintek, EPA Region 5, for providing Liquid Chromatographic Mass Spectrometric analyses of the various wipes tested. 


\section{Abbreviations/Acronyms}

Ace - Acetone

$\mathrm{CCV}$ - Continuing calibration verification

CWA - Chemical Warfare Agent, in the context of this report, the CWAs of interest are HD, GB, GD, GF, and VX

CWA-SAP - Standard Analytical Protocol for Extractable Semivolatile Organic Compounds ${ }^{8}$

DCM - Dichloromethane

DFTPP - Decafluorotriphenylphosphine

EPA - United States Environmental Protection Agency

EtOAc - Ethyl acetate

GB - Sarin

GC - Gas Chromatograph

GC/MS - Gas Chromatography/Mass Spectrometry

GC-TOF-MS - Gas Chromatography-Time-of-Flight-Mass Spectrometry

GD - Soman

GF - Cyclosarin

GFF - Glass fiber filter

$\mathrm{H}_{2} \mathrm{O}$ - Water

HD - Distilled sulfur mustard

IAG - Interagency Agreement

IPA - Isopropanol

LC/MS- Liquid Chromatography/Mass Spectrometry

LLNL - Lawrence Livermore National Laboratory

$\mathrm{MeOH}$ - Methanol

MS - Mass Spectrometer

NHSRC - National Homeland Security Research Center, Cincinnati, OH

NMR - Nuclear Magnetic Resonance Spectroscopy

OP - Organophosphorus (as in organophosphorus pesticide)

PFTBA - Perfluorotributylamine

QAPP - Quality Assurance Project Plan

TIC - Total Ion Chromatogram

TIC - Toxic Industrial Chemical

VX - O-ethyl-S-(2-diisopropylaminoethyl) methylphosphonothioate 


\section{Executive Summary}

Despite the fact that wipe sampling is commonly performed and the data produced by this technique is used to make numerous decisions, there is not an overwhelming consensus on the best method for collecting a wipe sample. It is generally agreed that, in order to produce reproducible quantitative results, consistent wetting solvents, wipe materials, sampling techniques, and sampling areas must be used. In addition, wetting solvents should be selected with consideration of the analyte of interest and wet wipes are better than dry wipes for the collection of organic chemicals. Thus, the goal of the Lawrence Livermore National Laboratory (LLNL) study was to understand factors affecting wipe sampling for specific chemical warfare agents (CWAs), including sarin (GB), soman (GD), cyclosarin (GF), distilled sulfur mustard (HD), and O-ethyl-S-(2-diisopropylaminoethyl) methylphosphonothioate (VX), and the pesticides diazinon and malathion.

One objective of this study was to investigate wipe materials and wetting solvents. The wipe materials studied included two cotton gauzes - Gauze 1 (Kendall-Curity) and Gauze 2 (Certified Safety), a glass fiber filter, and a cellulose fiber filter (Whatman 42). The wetting solvents investigated included dichloromethane (DCM), 50/50 (v/v) acetone/dichloromethane (Ace/DCM), hexane, and isopropanol (IPA). This study focused on the wipe sampling of the surfaces of stainless steel and glass because these surfaces have no porosities and are expected to provide optimum analyte recoveries. To the extent possible, we investigated only analytical methods questions and not those of environmental persistence of CWAs. A second study objective was to perform a month-long study in order to determine the stability of the sampled CWAs on the best wipe materials.

The process of evaluating the wipes included extraction of the wipe materials with several solvents to determine potential contaminants/interferences and to determine if precleaning of the wipe materials was necessary prior to sampling. All wipe materials were extracted with several different solvents, including DCM, 50/50 Ace/DCM, hexane, IPA, and 25/50/25 Ace/DCM/EtOAc, prior to gas chromatography/mass spectrometry (GC/MS) analyses. The wipes were also extracted with $90 / 10(\mathrm{v} / \mathrm{v})$ methanol/water $\left(\mathrm{MeOH} / \mathrm{H}_{2} \mathrm{O}\right)$ and analyzed by liquid chromatography/mass spectrometry (LC/MS). Initially, it was thought that the different extraction solvents might extract different contaminants from the wipes. However, examination of the data showed that the chromatographic profiles of contaminants extracted were relatively consistent, regardless of extraction solvent. Gauze 1 was found to contain high levels of impurities, including hydrocarbons, industrial compounds, and plant sterols. None of the ASTM Method D7599 - 09 ethanolamines, which are CWA precursors, was detected by LC/MS in Gauze 1. Gauze 2 was determined to have even higher levels of impurities than Gauze 1. Impurities of Gauze 2 included hydrocarbons, fatty acids, and industrial compounds. When analyzed by LC/MS, Gauze 2 was found to contain high concentrations of triethanolamine and diethanolamine. The glass fiber filters contained lower levels of contamination, as detected by 
GC/MS, than either of the gauzes. The majority of the contaminants were either hydrocarbons or phthalates. However, a very large amount of an unknown compound was detected by LC/MS. The Whatman 42 filters had low levels of contamination (mostly hydrocarbons and phthalates), as determined by GC/MS and no ethanolamines were detected by LC/MS. Given the amounts of contamination present, it is recommended that cleaning of wipes, prior to their use for sampling, is warranted.

Of the materials examined, Gauze 1 was found to be the most universally acceptable material, considering its cleanliness (e.g. its ability to be easily precleaned), structural integrity, and ability to retain wetting solvent. Gauze 2 was less desirable because it was found to contain a greater amount of potential interferences and it was difficult to clean. Because Gauze 2 absorbed much of the extraction solvent (and to a greater extent than did Gauze 1), it was more difficult to transfer the Gauze 2 sample extract from the extraction vial into a clean vial than for any of the other wipe materials tested. The Whatman 42 fiber filter did not retain the wetting solvent and did not recover VX. While easy-to-clean, the glass fiber filter was reasonably useful; however, it lacked structural integrity and did not retain as much wetting solvent during sampling as did the cotton gauzes.

DCM, 50/50 Ace/DCM, hexane, and IPA were tested as wetting solvents for wipe sampling. Given the scatter in the data, a clear "best solvent" for CWA sampling could not be identified. From an operational perspective, and because these solvents are the least prone to evaporation, IPA and hexane were preferred as wetting solvents. In general, CWA recoveries determined by wipe sampling were not as good as those observed by direct solvent extraction of the surface. During extraction experiments, it was observed that potential matrix enhancement effects produced recoveries $>100 \%$ for certain analytes (most notably VX and malathion).

The stability of CWAs spiked on wetted Gauze 1 wipes and glass fiber filters was studied. Data suggested that a sample holding time of one to two weeks for samples containing CWAs might be appropriate for Gauze 1 and for the glass fiber filter (with the exception that VX cannot be sampled with the glass fiber filter). 


\section{Table of Contents}

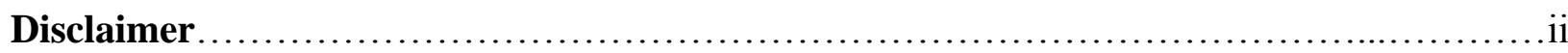

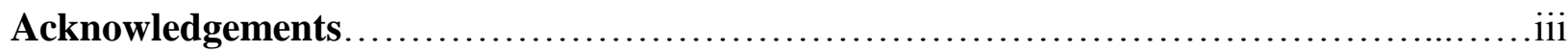

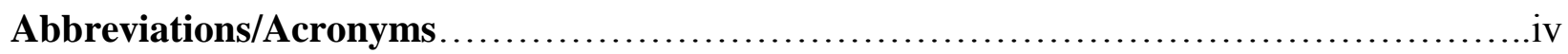

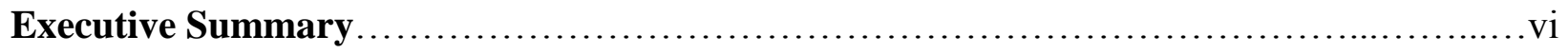

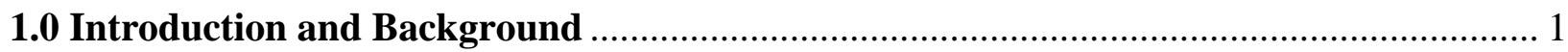

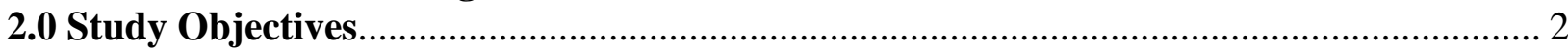

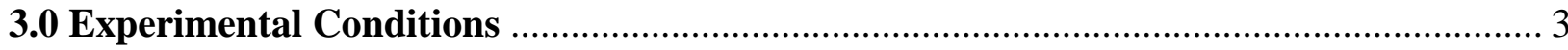

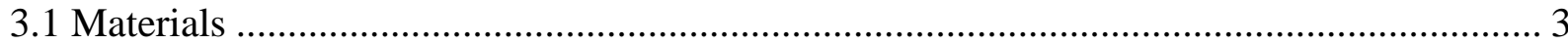

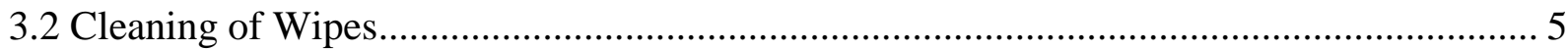

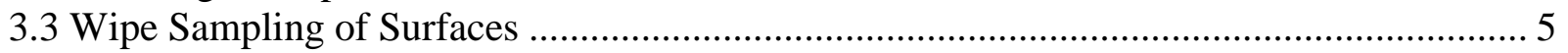

3.4 Extraction of Wipes to Determine Interferences …………............................................. 5

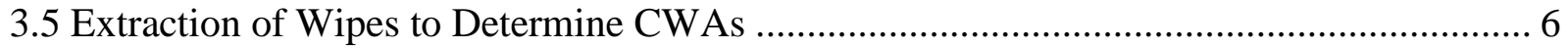

3.6 Analysis of Wipe Extracts ....................................................................................... 7

3.7 Holding Time Studies ............................................................................................. 7

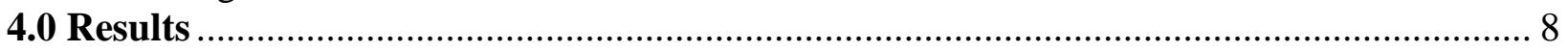

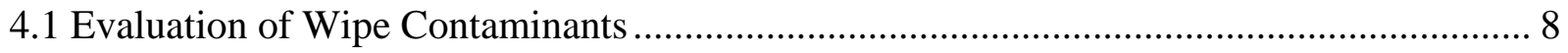

General observations during extraction ....................................................................... 14

Tentative identification of wipe contaminants.................................................................. 14

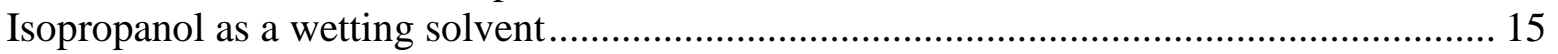

4.2 CWA Recoveries from Precleaned Wipes versus Wipes used as Received ....................... 16

4.3 Extraction Efficiencies for Various Wipes and Wetting Solvents..................................... 19

4.4 Sample Holding Times for CWAs on Selected Wipes ..................................................... 25

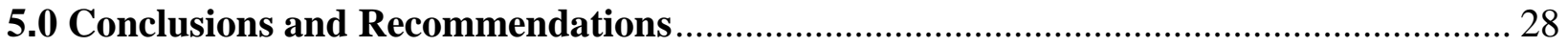

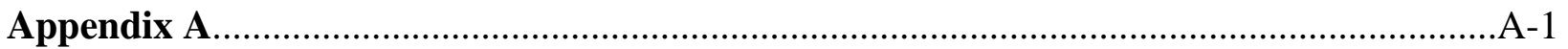




\subsection{Introduction and Background}

Because wipe sampling can be performed easily, rapidly, and without destruction of the surface to be tested, there is some incentive to investigate this method of sample collection. For example, direct extraction of surfaces such as walls, floors, and furniture is often not feasible; thus, wipe sampling is the method of choice for recovering chemical warfare agents (CWAs) from these surfaces. However, wipe sampling does not remove as much analyte from a material as does direct extraction, which provides more reliable quantitative data. Wipe sampling can only remove analyte from the surface of a material. In contrast, direct extraction of a bulk material can also remove analytes which have penetrated a material. For this reason, it is important to understand the efficiencies with which wipe sampling collects analytes in comparison to direct extraction of bulk materials and it is important to understand the quantities of CWA that might still be present in a material after wipe sampling is performed.

Despite the fact that wipe sampling is commonly performed and the data produced by this technique is used to make numerous decisions, in a recent review of wipe sampling, ${ }^{1}$ it was concluded that "there is not an overwhelming consensus on how to take a wipe sample for collecting CWAs, OP pesticides, and other TICs from surfaces." In order to produce quantitative results, consistent wetting solvents, wipe materials, sampling techniques, and sampling areas must be used. Earlier work by the United States Environmental Protection Agency (EPA) found that "Experience and consistency of technique were determined to play significant roles concerning the overall accuracy and precision, in obtaining surface samples." ${ }^{2}$ In addition, that same study concluded that wetted wipes collected more analyte than did dry wipes, that wetting solvents should be selected with consideration of the analyte of interest, that there was an apparent correlation between surface area of the wipe material and analyte recovery, and that analyte recoveries depended, in part, on the porosity of a surface.

The goal of the Lawrence Livermore National Laboratory (LLNL) study was to understand factors affecting wipe sampling for specific CWAs, including sarin (GB), soman (GD), cyclosarin (GF), distilled sulfur mustard (HD), and O-ethyl-S-(2-diisopropylaminoethyl) methylphosphonothioate (VX), and the pesticides diazinon and malathion. When considering CWAs, the interpretation of results of past studies of wipe efficiencies, performed by LLNL and

${ }^{1}$ A Literature Review of Wipe Sampling Methods for Chemical Warfare Agents and Toxic Industrial Chemicals, EPA/600/R-07/004, January 2007, prepared by Battelle, Columbus, OH 43201, for Stephen Billets, U.S. Environmental Protection Agency, Office of Research and Development National Exposure Research Laboratory, Environmental Sciences Division, Las Vegas, NV 89119.

${ }^{2}$ Sampling of Common Pesticides and PCBs from Inert Surfaces, EPA/330/1-90-001, October 1989, B. L. Carr and D. F. Hill, National Enforcement Investigations Center, Denver, CO. 
by others, ${ }^{3}$ is complicated because of the compounding effects of analyte volatilization and degradation. To the extent possible, we investigated only analytical methods questions and not those of environmental persistence of CWAs (i.e. the persistence of the CWAs on the surfaces to be sampled). Both LLNL and Battelle have performed wipe sampling studies. These studies showed that low concentrations of chemical agents deposited directly on the surface of cotton gauze could be recovered acceptably. Battelle found (as had LLNL) that wiping of smooth surfaces of minimal porosity (e.g. galvanized metal, vinyl tile, and painted concrete surfaces) produced the greatest analyte recoveries. ${ }^{4,5}$ Considering these results, and also discussions with numerous stake-holders, this study focused on the wipe sampling of the surfaces of stainless steel and glass because these surfaces have no porosities and are expected to provide optimum analyte recoveries. Specifically, this study sought to standardize the methods chosen for wipe sampling of the selected CWAs and to investigate such variables as wipe material and wetting solvent. Once an optimal wipe and wetting solvent combination was selected, we performed a monthlong study to determine the stability of the sampled CWAs on the wipe (e.g. sample holding time).

\subsection{Study Objectives}

Our first goal was to investigate wipe materials and wetting solvents. Various cotton gauzes, a glass fiber filter, and a Whatman 42 cellulose fiber filter were tested as wipe materials. Cotton gauze is commonly-used to collect organic compounds from a variety of surfaces, and it was used by both LLNL and Battelle in previous studies. Glass fiber and cellulose filters have been used in other studies and were expected to provide minimal background interferences. We also investigated if the wipe materials would require cleaning prior to using them to sample surfaces.

In the context of this study, the term "wetting solvent" was used to indicate the solvent that was used to saturate the wipe and aid in the transfer of the analyte from the surface being studied to the wipe. "Wetting solvent" is distinctly different from "extraction solvent", the term which was used to indicate the solvent used to remove the target analytes from the wipe material. Wetting solvents investigated encompassed a range of polarities and included 50/50 (v/v) dichloromethane/acetone (DCM/Ace) and isopropanol (IPA), both of which were used by Battelle in previous studies, DCM alone, and hexane. While it was expected that the DCM-

3 Testing and Evaluation of Wipe Sampling Methods for Collecting Chemical Warfare Agents (CWAs), CWA Degradation Products, and Toxic Industrial Chemicals from Surfaces, August 10, 2008, Prepared by Battelle, Columbus, OH 43201, for Stephen Billets, U.S. Environmental Protection Agency, Office of Research and Development National Exposure Research Laboratory, Environmental Sciences Division, Las Vegas, NV 89119.

${ }^{4}$ Battelle, August 10, 2008.

5 Efficacy of Liquid and Foam Decontamination Technologies for Chemical Warfare Agents on Indoor Surfaces, A. H. Love, C. G. Bailey, M. L. Hanna, S. Hok, A. K. Vu, D. J. Reutter, and E. Raber, J. Haz. Mat. 2011, 196, 115122. 
based solvents would work well for sampling CWAs, the advantages of using IPA and hexane in the field are that these solvents pose less of a human health risk than DCM and that they are not expected to be as destructive to surfaces as is DCM. Thus, it is important to understand the effectiveness of all of these solvents as wetting agents. To focus on the efficacy of the wetting solvents, we chose to investigate the simple, non-porous surfaces of glass and stainless steel. Note that these surfaces would not be damaged by any of the solvents to be tested.

The second goal was to determine the length of time for which CWAs spiked on wetted wipes are stable. This stability study was performed with DCM as the wetting solvent and both the glass fiber filter and the Kendall Curity cotton wipe were tested. Experimental work was conducted in accordance with a previously established Quality Assurance Project Plan (QAPP). ${ }^{6}$

\subsection{Experimental Conditions}

\subsection{Materials}

The following wipe materials were tested:

Gauze 1:

Kendall-Curity gauze wipes, 3 in. x 3 in., 12-ply, P/N 1903, available from Tyco Heathcare Group LP, Mansfield, MA, Lot\# 7107500

Gauze 2:

Certified Safety Manufacturing, Inc. Certi-Gauze Pads, 3 in. x 3 in., sterile, P/N 19-065-723, available from Fisher Scientific, Pittsburg, PA, Lot\# 500.8

Glass Fiber Filter: $\quad$ Advantec GA55 glass fiber filters, $47 \mathrm{~mm}$ i.d., $1.6 \mu \mathrm{m}$ pore size, $0.22 \mathrm{~mm}$ thickness, P/N EW-06646-02, available from Cole-Parmer, Vernon Hills, IL, Lot\# 80730709

Whatman 42 Filter: Quantitative Filter Papers, $55 \mathrm{~mm}$ i.d, $2.5 \mu \mathrm{m}$ pore size, P/N EW-0664721, available from Cole-Parmer, Lot\# J11448649

${ }^{6}$ Quality Assurance Project Plan and Study Plan for Lawrence Livermore National Laboratory's Wipe Sampling Collection Efficiencies and Holding Time Studies For EPA under IAG \#DW89922616-01-0, Rev. 2.1, C. Koester, December 21, 2009, LLNL-TR-415616. 
Solvents used for the wipe study included:

Acetone (Ace): $\quad$ Fluka, purchased from Sigma-Aldrich, Lot\# 7262M

Dichloromethane (DCM): $\quad$ Riedel-de Haen, purchased from Sigma-Aldrich, Lot\# 7284M

Ethyl acetate (EtOAc): $\quad$ Riedel-de Haen, purchased from Sigma-Aldrich, Lot\# 7125M

Hexane: $\quad$ Fluka, purchased from Sigma-Aldrich, Lot\# 1351600

Isopropanol (IPA): $\quad$ Riedel-de Haen, purchased from Sigma-Aldrich, St. Louis, MO, Lot \# 7334A

The solvents were used directly from the bottles or mixed, on a volume to volume basis, to obtain the required solvent composition.

Chemical standards were prepared in dichloromethane; some were obtained from commercial vendors and some were synthesized in-house. CWA standards used for this study were synthesized by LLNL. GB, GD, and GF were synthesized by converting dichlor to difluor and reacting it with the appropriate alcohol. HD was synthesized by reaction of thiodiglycol and thionyl chloride. VX was synthesized by an optimized, in-house method. All standards synthesized in-house underwent purity checks by nuclear magnetic resonance spectroscopy (NMR) and/or gas chromatography/mass spectrometry (GC/MS) prior to use. Dilute standards were prepared gravimetrically from neat materials.

Neat malathion, Pestanal Grade from Fluka (P/N 26143, Lot\# 7169X), and diazinon, also from Fluka as $100 \mathrm{ng} / \mu \mathrm{L}$ in acetonitrile (P/N 45842, Lot\# SZE7250X), were purchased from Sigma Aldrich, St. Louis, MO.

The glass surfaces used in wipe studies were cut into coupons of approximately $7 \mathrm{~cm}^{2}$ and the stainless steel coupons were $9 \mathrm{~cm}^{2}$ which allowed them to fit into 2-oz jars for extraction. The specifics of the surfaces used were:

Glass: $\quad$ In the form of microscope slides, P/N 48300-047, available from VWR International, West Chester, PA

Stainless steel: $\quad$ Type 304 and available from previous project, used in the form of $3 \mathrm{~cm} \mathrm{x}$ $3 \mathrm{~cm}$, square coupons 


\subsection{Cleaning of Wipes}

Soxhlet extraction was the method selected to preclean the Whatman 42 paper and the gauze wipes. These materials were precleaned, by extracting for 10 cycles, using the final extraction solvent of 25/50/25 (v/v/v) Ace/DCM/EtOAc. The glass fiber filters were precleaned by placing them in a muffle furnace at $450^{\circ} \mathrm{C}$ for 5 hours.

\subsection{Wipe Sampling of Surfaces}

Small surface coupons were spiked with CWAs, malathion, and diazinon from a multicomponent, dilute solution (100 ppm), in dichloromethane. Appropriate volumes of this solution were deposited on the matrices of interest using calibrated pipets. The coupons were directly extracted or wipe sampled as soon as solvent evaporation was complete to minimize the possibility of CWA losses due to evaporation or surface reactions. A consistent, predetermined volume of solvent was used to wet each wipe material such that the wipe was almost saturated, $3.0 \mathrm{~mL}$ for the cotton gauzes and $0.5 \mathrm{~mL}$ for the paper and glass filters. Surfaces were sampled by first using a horizontal "Z" shaped pattern to wipe the entire surface of the coupon; then, a clean surface of the wipe was exposed to again wipe the surface in a vertical "Z" pattern. The coupons were held stationary during the wiping operation with solvent-rinsed forceps. The wipe or coupon was immediately placed in a 40-mL VOA vial and extracted to determine CWA removed from the surface.

\subsection{Extraction of Wipes to Determine Interferences}

Solvent extractions were performed on four selected wipe materials to determine the identities of potential contaminants and to determine if cleaning of the wipe materials prior to sample collection was needed. The selected wipe materials were extracted, in duplicate, using five different solvents; see Table 1. These solvents included both those to be tested as wetting solvents - DCM, 50/50 (v/v) Ace/DCM, hexane, and IPA - and 25/50/25(v/v/v) Ace/DCM/EtOAc, which was used as the extraction solvent. Each wipe was extracted twice. The wipe was first extracted for 30 minutes, by waterbath sonication (ambient temperature), with $15 \mathrm{~mL}$ of the appropriate extraction solvent. The resulting sample extract was then transferred, by decanting and/or pipeting, into a clean, $40-\mathrm{mL}$ VOA vial. The wipe was then extracted, as described above, a second time using another $15-\mathrm{mL}$ aliquot of the desired solvent. The resulting solvent extract was removed and added to the previous sample extract in the $40-\mathrm{mL}$ VOA vial. The combined extract (approximate volume of $30 \mathrm{~mL}$ ) was reduced to below $1.0 \mathrm{~mL}$, using a gentle flow of nitrogen and mild heat $\left(40^{\circ} \mathrm{C}\right)$ with a RapidVap unit. Under these conditions, it took approximately an hour for the sample extract to evaporate to a volume of 1 $\mathrm{mL}$. The concentrated extract was transferred to an autosampler vial, the volume adjusted to 1.0 $\mathrm{mL}$ using the extraction solvent, and, then, sufficient internal standard stock solution was added to provide a concentration of $1.0 \mu \mathrm{g} / \mathrm{mL}$ for each compound. The resulting extracts were analyzed by GC/MS, operated in full scan mode. Potential contaminants were tentatively identified based 
on matches of the mass spectra for the samples and spectra contained in the NIST '08 Mass Spectral Database.

The samples were analyzed for ethanolamines (specifically diethanolamine, triethanolamine, $\mathrm{N}$-methyldiethanolamine, and N-ethyldiethanolamine) by ASTM Method D7599 - 09. ${ }^{7}$ This analysis was done because ethanolamines are precursors of certain CWAs and have been observed as contaminants on some types of wipes. Prior to ethanolamine analyses, the wipes were extracted by soaking them in $10 \mathrm{~mL}$ of $90 / 10(\mathrm{v} / \mathrm{v})$ methanol/water $\left(\mathrm{MeOH} / \mathrm{H}_{2} \mathrm{O}\right)$. The resulting sample extracts were analyzed by liquid chromatography/mass spectrometry (LC/MS). The wipe samples were analyzed by chemists of the EPA Region 5 Laboratory (Chicago, IL).

Table 1. Wipe samples extracted and analyzed for interferences.

\begin{tabular}{|c|c|c|c|c|c|c|}
\hline \multirow[b]{3}{*}{ Wipe Material } & \multicolumn{6}{|c|}{ Number of Samples to be Extracted by Each Solvent and Analyzed } \\
\hline & \multicolumn{5}{|c|}{ GC/MS } & \multirow{2}{*}{$\begin{array}{c}\mathrm{LC} / \mathrm{MS} \\
\text { 90/10 } \mathrm{MeOH} / \mathrm{H}_{2} \mathrm{O}\end{array}$} \\
\hline & DCM & $\begin{array}{c}\mathbf{5 0 / 5 0} \\
\text { Ace/DCM }\end{array}$ & Hexane & IPA & $\begin{array}{c}25 / 50 / 25 \\
\text { Ace/DCM/EtOAc }\end{array}$ & \\
\hline Gauze 1 & 2 & 2 & 2 & 2 & 2 & 2 \\
\hline Gauze 2 & 2 & 2 & 2 & 2 & 2 & 2 \\
\hline Glass Fiber & 2 & 2 & 2 & 2 & 2 & 2 \\
\hline Whatman 42 & 2 & 2 & 2 & 2 & 2 & 2 \\
\hline Solvent Blank & 1 & 1 & 1 & 1 & 1 & 1 \\
\hline
\end{tabular}

Notes: DCM=dichloromethane, Ace=acetone, IPA=isopropyl alcohol, EtOAc=ethyl acetate, and $\mathrm{MeOH}=$ methanol.

\subsection{Extraction of Wipes to Determine CWAs}

The extraction process followed the Draft Standard Analytical Protocol for Extractable Semivolatile Organic Compounds (CWA-SAP). ${ }^{8}$ Note that ongoing work in our laboratory suggests that, in the future, it will be possible to reduce the extraction time listed in the CWA-

\footnotetext{
7 ASTM Method D7599 - 09, Standard Test Method for Determination of Diethanolamine, Triethanolamine, N-Methyldiethanolamine and N-Ethyldiethanolamine in Water by Single Reaction Monitoring Liquid Chromatography/Tandem Mass Spectrometry (LC/MS/MS), 2009.
}

\footnotetext{
${ }^{8}$ Draft Standard Analytical Protocol for Extractable Semivolatile Organic Compounds, Revised Draft, September 2008, U.S. Environmental Protection Agency.
} 
SAP to 5-10 minutes. Quality assurance experiments performed during the extraction of wipes included extraction control, solvent spike control, and extraction solvent spike and evaporation control experiments. Extraction controls consisted of $1 \mu \mathrm{g}$ each CWA and pesticide spiked directly on the surface and extracted with a solvent. Solvent spike controls consisted of $1 \mu \mathrm{g}$ each CWA and pesticide spiked directly into $1.00 \mathrm{~mL}$ of DCM. Extraction solvent spike and evaporation controls consisted of $1 \mu \mathrm{g}$ each CWA and pesticide spiked directly into $30.00 \mathrm{~mL}$ of the extraction solvent, which was then evaporated to a volume of $1.00 \mathrm{~mL}$.

\subsection{Analysis of Wipe Extracts}

GC/MS analyses were performed with an Agilent 5973 mass spectrometer (MS, Agilent Technologies, Inc., Santa Clara, CA) coupled with an Agilent 6890 gas chromatograph (GC). The GC/MS was tuned, as needed, with perfluorotributylamine (PFTBA), using the vendor's algorithms. Prior to analysis of samples, $50 \mathrm{ng}$ of decafluorotriphenylphosphine (DFTPP) were injected into the GC/MS and used to establish that the GC/MS was functioning properly. The GC column used was an Agilent DB-5, MS, Ultrainert column (30 m x 0.25 mm i.d. x $0.25 \mu \mathrm{m}$ ). Each batch of samples was analyzed with a corresponding method blank. During the course of analysis, continuing calibration verification (CCV) standards near the midpoint of the calibration range were analyzed and the responses of these standards were within $20 \%$ of that of the initial calibration in order for the data collected between CCV checks to be considered valid. For GC/MS analyses, surrogate and internal standards used were consistent with those of EPA Method $8270^{9}$ and of the CWA-SAP ${ }^{8}$.

Analyses were also performed with with a time-of-flight (TOF) MS, using a LECO Pegasus system (LECO Corporation, St. Joseph, MI) coupled with an Agilent 6890 GC. The GC-TOF-MS was tuned, as needed, with PFTBA, using the vendor's algorithms. Prior to analysis of samples, $10 \mathrm{ng}$ of DFTPP were injected into the GC-TOF-MS to establish that it was functioning properly. The GC column used was an Agilent DB-5, MS, Ultrainert column (20 m x $0.18 \mathrm{~mm}$ i.d. x $0.18 \mu \mathrm{m}$ ). Sample blanks and CCVs were analyzed, as previously described, to provide assurance that the quality of the data was good.

\subsection{Holding Time Studies}

Initial experiments with IPA. Because it was anticipated that IPA might not be an appropriate solvent to allow collection of G-agents (IPA is miscible with water, and there is a concern that "wet" IPA could cause hydrolysis of G-agents), a short study was conducted to determine if the use of IPA as a wetting agent would be problematic. Onto six Kendall-Curity cotton gauze wipes that were wetted with $3.0 \mathrm{~mL}$ of IPA, $10 \mu \mathrm{g}$ of each CWA were spiked from a dilute solution. Three wipes were immediately extracted and analyzed and the remaining three wipes were sealed in vials and stored at $\sim 4{ }^{\circ} \mathrm{C}$ for 2 days. After two days of storage, the wipes

${ }^{9}$ Method 8270D: Semivolatile Organic Compounds by Gas Chromatography/Mass Spectrometry (GC/MS), Rev. 4, February 2007, U.S. Environmental Protection Agency. 
were extracted and analyzed to determine if significant degradation of the CWA had occurred. The wipes were extracted according to the CWA-SAP.

Final experiments with optimal wipes. Experiments were conducted to determine the length of time for which CWAs spiked on dichloromethane-wetted wipes, at amounts of $1 \mu \mathrm{g}$ and $0.1 \mu \mathrm{g}$, were stable. CWAs were spiked on the wetted wipes, stored in closed VOA vials in a refrigerator $\left(\sim 4^{\circ} \mathrm{C}\right)$, and analyzed on Days $0,2,7,14$, and 30 to determine the stability of the analytes during the course of thirty-day storage.

\subsection{Results}

\subsection{Evaluation of Wipe Contaminants}

Initial studies were performed to evaluate the cleanliness of various wipe materials, to determine the nature of contaminants that were present in the wipes, and to determine if cleaning of the wipes was necessary prior to using them for sample collection. The wipe materials tested were cotton gauze pads from Kendall Curity (Gauze 1) and from Certified Safety (Gauze 2), a cellulose filter paper (Whatman 42), and a glass fiber filter (GFF). The wipes were extracted, as previously described, with solvents of different polarities, including DCM, 50/50 (v/v) Ace/DCM, 25/50/25 Ace/DCM/EtOAc, hexane, and IPA. The resulting extracts were analyzed by GC/MS, operated in full scan mode, to tentatively identify potential contaminants (e.g. identification was based on spectral matches with the NIST '08 Mass Spectral Database). Total ion chromatograms (TICs) produced from the extraction of each wipe material by various solvents are shown in Figures 1-5. Appendix A provides more detailed views of individual TICs produced for each solvent and wipe combination. 


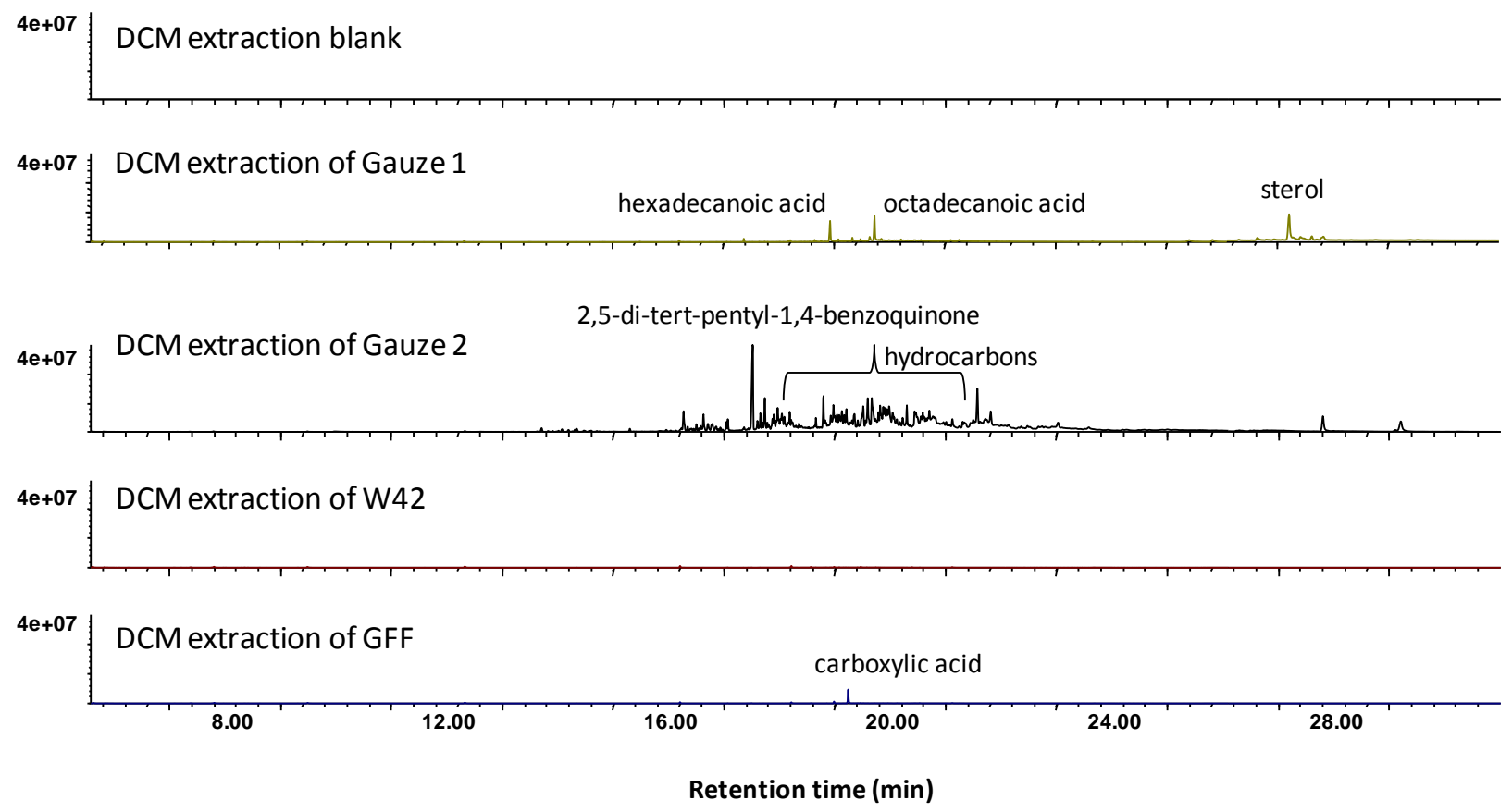

Figure 1. Total ion chromatograms produced when Gauze 1, Gauze 2, Whatman 42 filter paper (W42), and glass fiber filter (GFF) were extracted with DCM. 


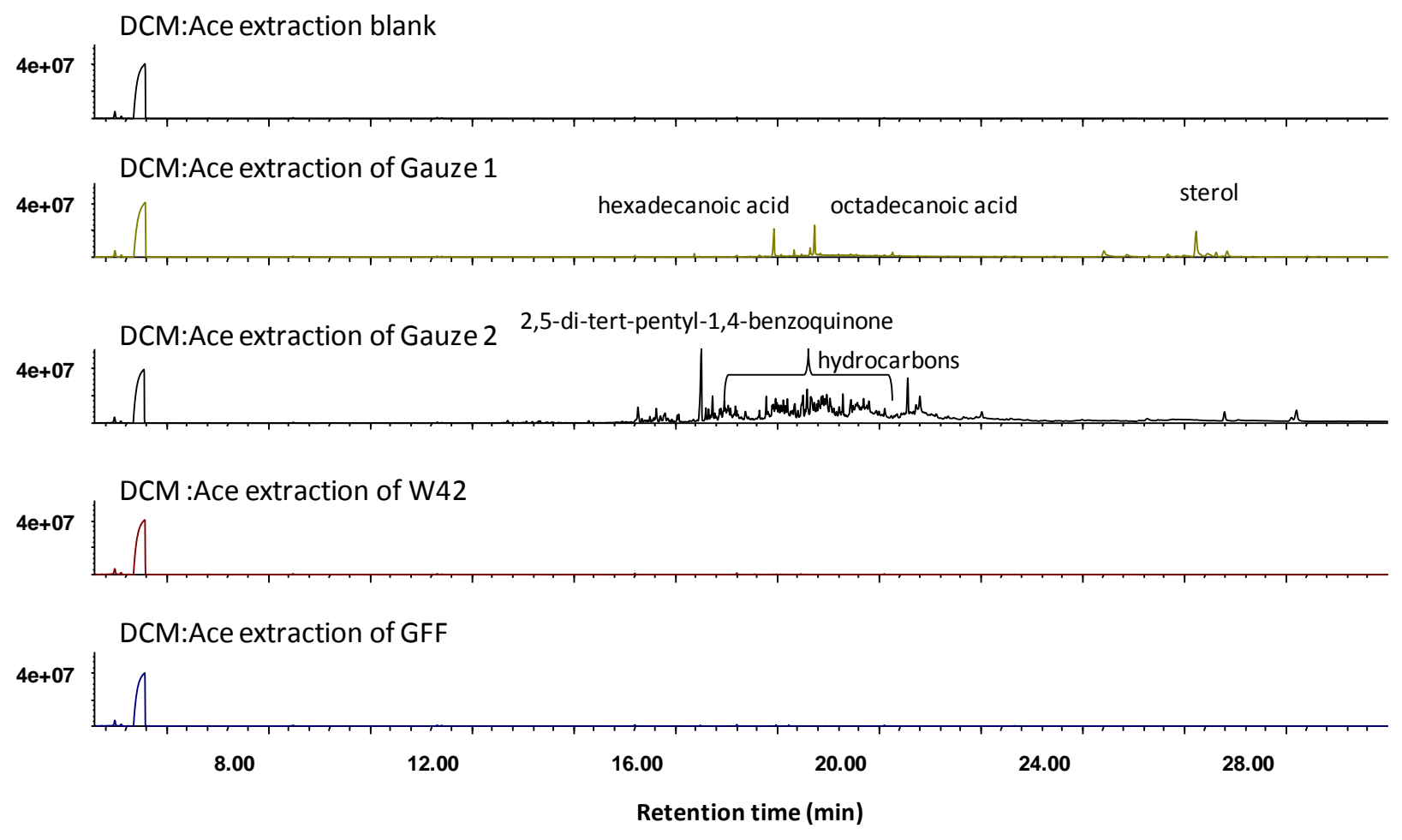

Figure 2. Total ion chromatograms produced when Gauze 1, Gauze 2, Whatman 42 filter paper (W42), and glass fiber filter (GFF) were extracted with 50/50 (v/v) DCM/Ace. 


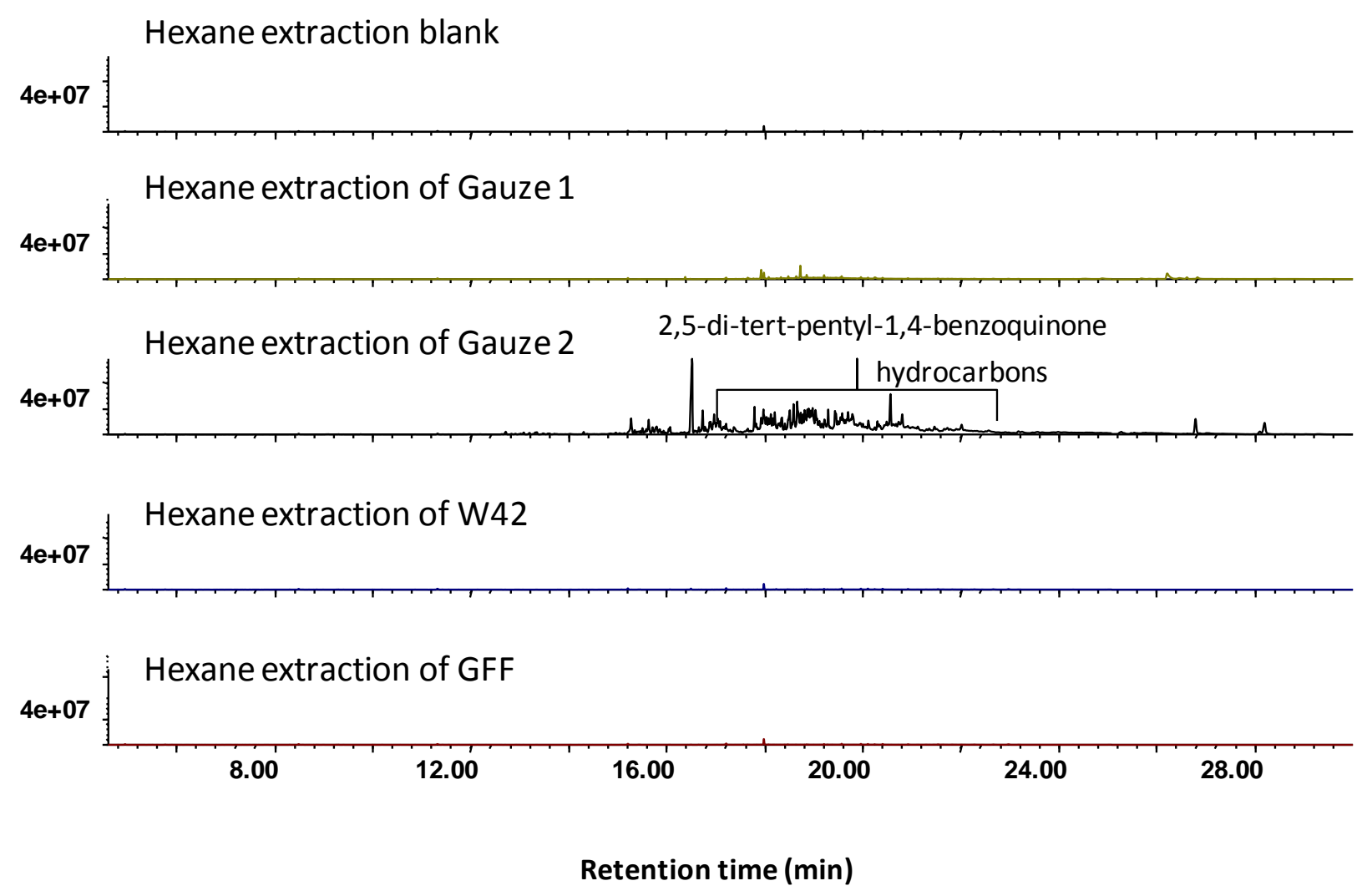

Figure 3. Total ion chromatograms produced when Gauze 1, Gauze 2, Whatman 42 filter paper (W42), and glass fiber filter (GFF) were extracted with hexane. 


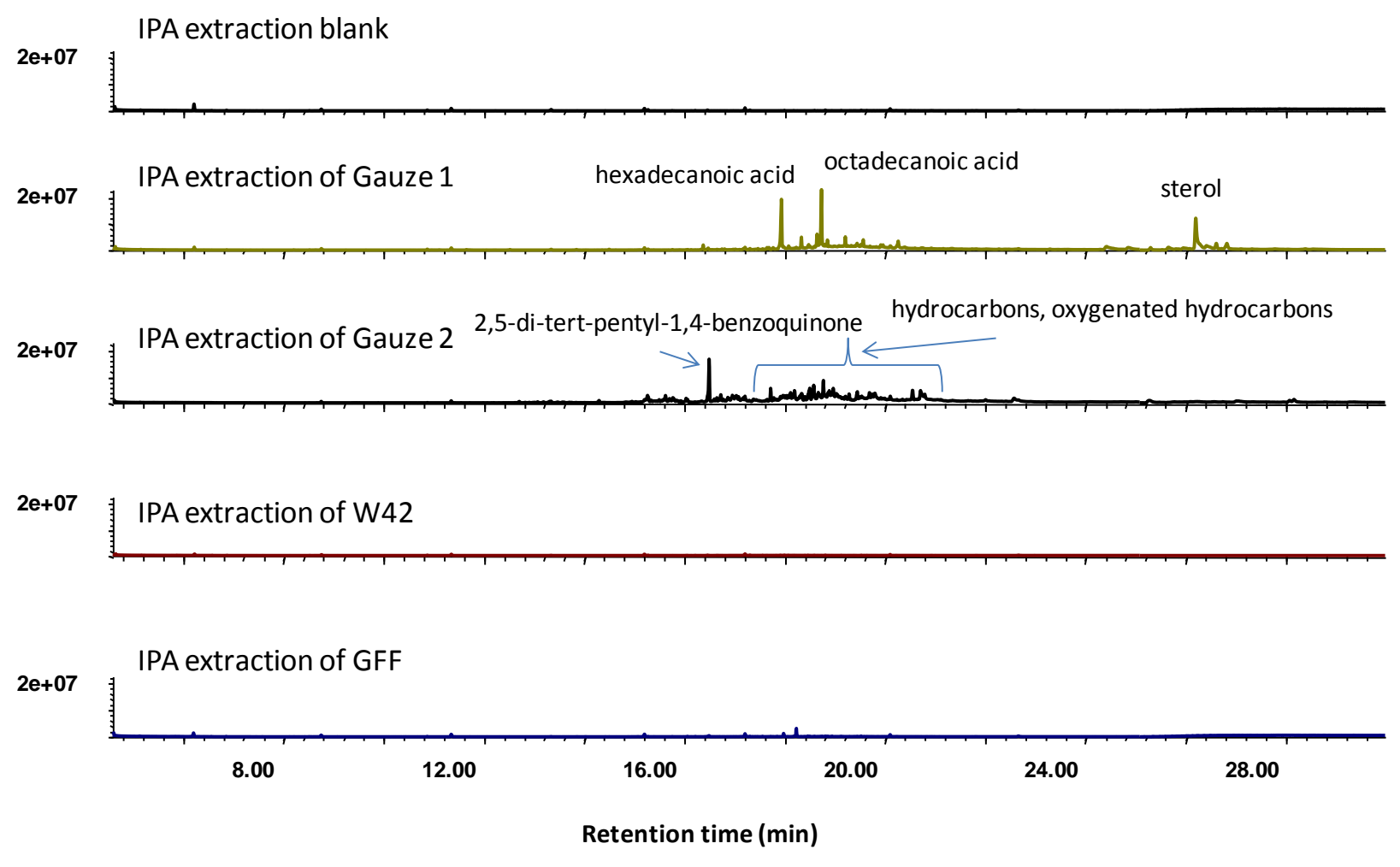

Figure 4. Total ion chromatograms produced when Gauze 1, Gauze 2, Whatman 42 filter paper (W42), and glass fiber filter (GFF) were extracted with IPA. 

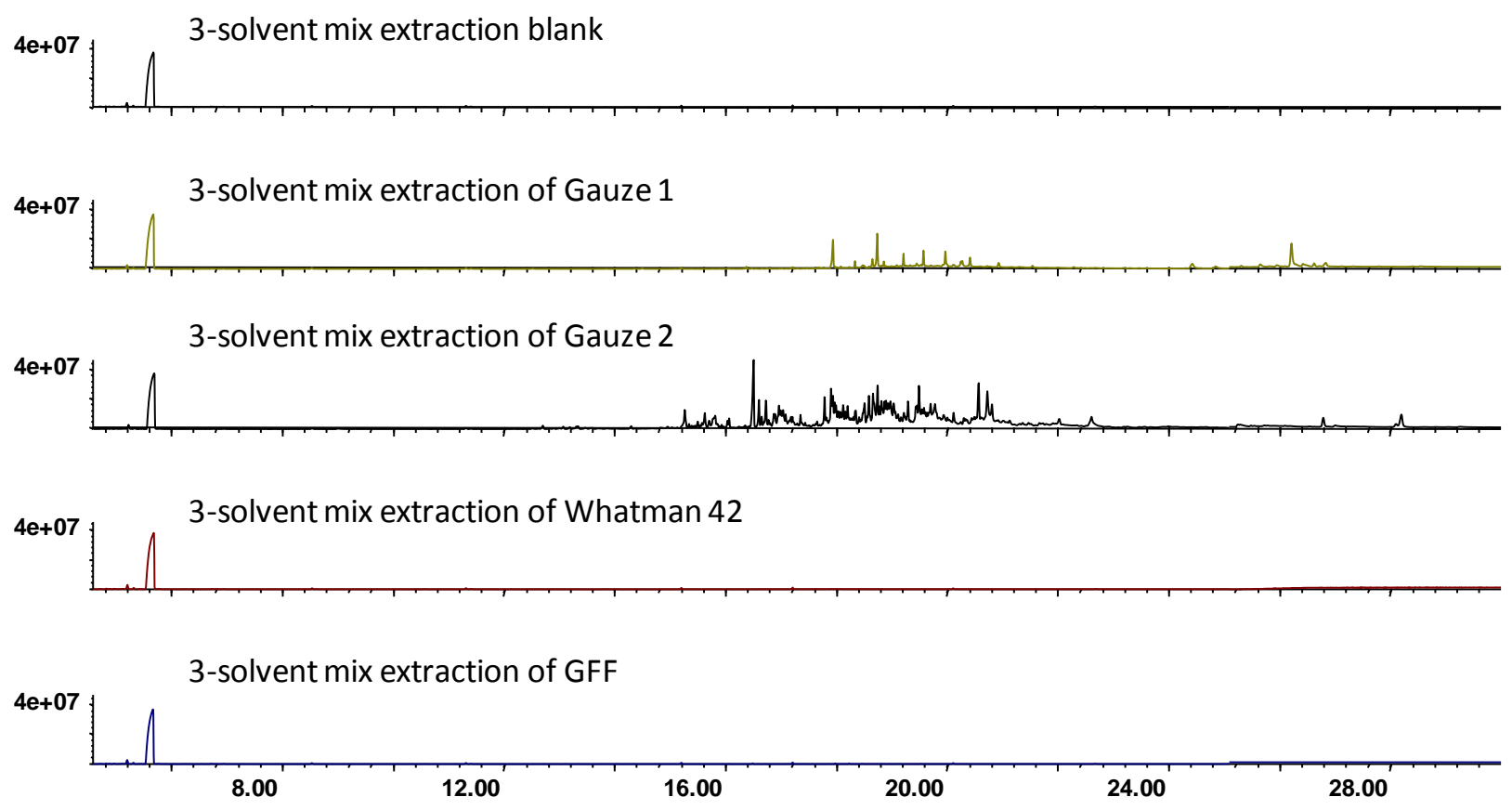

Retention time (min)

Figure 5. Total ion chromatograms produced when Gauze 1, Gauze 2, Whatman 42 filter paper (W42), and glass fiber filter (GFF) were extracted with 25/50/25 (v/v/v) Ace/DCM/EtOAc (3-solvent mix). Note that contaminants observed were the same as those of Figure 4. 
General observations during extraction

Gauze 1 (Kendall-Curity) was previously used for the wipe studies by both LLNL and by Battelle and consisted of loosely woven fibers. When this material was extracted with solvents, some of the fibers (i.e. insoluble material) were transferred to the extraction vials. The fibers had different appearances in the different extraction solvents. For example, the fibers had the appearance of a dispersed colloidal dispersion in the DCM extracts, but coagulated as a precipitate in Ace/DCM. In the DCM extracts, the fibrous material floated on the surface of the solvent, and remained on the solvent surface, even after centrifugation (10 minutes at $287 g$ ). In Ace/DCM, the fibers present were observed to settle, by gravity (e.g. no centrifugation needed), to the bottom of the sample vial overnight. Fibers were also present in the hexane extract, but the fibers adhered to the sides of the glass vials. The amount and appearance of the insoluble material collected in Ace/DCM/EtOAc was different for the duplicate extract concentrates - one sample extract appeared clear, with few discrete fibers, and the other extract had a dispersed, colloidal suspension of insoluble material.

Gauze 2 (Certified Safety), had the appearance of bonded cotton fibers, resulting in a mechanically durable pad. All solvent extracts were clear, with no insoluble material present.

The glass fiber filters shed particles during the extraction process. When extracted with DCM, a large amount of glass fibers were removed during the sonication process and transferred to the autosampler vials. The fibers were compacted to the bottom of the autosampler vial by centrifugation (10 minutes at 287g) and did not interfere with GC/MS analysis. Glass fibers were also observed with Ace/DCM, with Ace/DCM/EtOAc, and with IPA and were compacted to bottom of the vial prior the analysis by centrifugation ( 5 minutes at $287 g$ ). Not many glass fibers were present in the hexane extracts of the GFFs; therefore, centrifugation was not necessary.

The Whatman 42 filter paper yield clear, colorless sample extracts, with no noticeable insoluble materials present.

Tentative identification of wipe contaminants.

All wipe materials were extracted with several different solvents, including DCM, 50/50 Ace/DCM, hexane, IPA, and 25/50/25 Ace/DCM/EtOAc, prior to GC/MS analyses. The wipes were also extracted with $90 / 10(\mathrm{v} / \mathrm{v}) \mathrm{MeOH} / \mathrm{H}_{2} \mathrm{O}$ and analyzed by $\mathrm{LC} / \mathrm{MS}$. Initially, it was thought that the different extraction solvents might extract different contaminants from the wipes. However, examination of Figures 1-5 show that the chromatographic profiles of contaminants extracted were relatively consistent, regardless of extraction solvent. However, the quantities of contaminants removed with IPA were about half those that were removed by the other solvents.

When analyzed by GC/MS, Gauze 1 was found to contain high levels of impurities, including hydrocarbons, industrial compounds, and plant sterols. None of the ASTM Method D7599 - 09 ethanolamines was detected by LC/MS. This is important as the ethanolamines 
listed in this method (ethyldiethanolamine, methyldiethanolamine, and triethanolamine) are precursors of certain CWAs and might serve as indicators that certain samples have been exposed to CWA when the agents themselves cannot be detected. In addition, ethyldiethanolamine, methyldiethanolamine, and triethanolamine are classified as Schedule 3 chemicals and are subject to regulation according to the Chemical Weapons Convention.

Gauze 2 was determined to have even higher levels of impurities than Gauze 1. Impurities of Gauze 2 included hydrocarbons, fatty acids, and industrial compounds. When analyzed by LC/MS, Gauze 2 was found to contain high concentrations of triethanolamine and diethanolamine.

The glass fiber filters contained lower levels of contamination, as detected by GC/MS, than either of the gauzes. The majority of the contaminants were either hydrocarbons or phthalates. However, a very large amount of an unknown compound was detected by LC/MS. Conversations with the vendor failed to shed light on the identity of this compound and the vendor claims that no binders were used in the production of the glass fiber filters.

The Whatman 42 filters had low levels of contamination (mostly hydrocarbons and phthalates), as determined by GC/MS. In addition, no ethanolamines were detected by LC/MS.

\section{Isopropanol as a wetting solvent}

Because it was anticipated that IPA might not be an appropriate solvent to allow collection of G-agents, a small study was conducted to determine if the use of IPA as a wetting agent would be problematic. An experiment was performed in which $10 \mu \mathrm{g}$ of each CWA were spiked onto Gauze 1 wipes that were wetted with IPA. The gauze wipes were used as received and were not cleaned prior to spiking. Three wipes were immediately extracted and analyzed and the remaining three wipes were sealed in vials and stored at $\sim 4{ }^{\circ} \mathrm{C}$ for two days. After two days, the wipes were extracted and analyzed to determine if significant degradation of the CWA had occurred. Paired $t$-tests were performed on the log-transformed, analyte amounts. Statistical analyses were performed on the logarithms of the measured concentrations because variability of concentration units increases with concentration, whereas variability in terms of percent change tends to be more stable as a function of concentration. There were no significant differences in the amounts of any of the CWAs recovered from the wipes on Day 0 and Day 2; see Table 2.

Note that initial analyses of the wipe extracts showed significant matrix enhancements, with measured VX concentrations at twice their expected values. Presumably, this matrix enhancement was attributed to contamination found on the wipes. Because of this effect, the continuing calibration checks for triphenyl phosphate and VX were not acceptable (e.g. did not meet the requirements of per EPA Method $8000 C^{10}$ ). To remedy this problem, the injection port

10 Method 8000C: Determinative Chromatographic Separations, Rev. 3, U.S. Environmental Protection Agency, March 2003. 
liner of the GC was conditioned with multiple injections of actual sample extracts (this conditioning process aided in stabilizing responses for both precleaned and uncleaned wipes). After the conditioning procedure was completed, a new calibration curve was generated; continuing calibration checks met the acceptance criteria. The samples were then reanalyzed and defensible data, shown in Table 2, were produced.

Table 2. Amount of CWAs (in micrograms) removed from Gauze 1 wipes wetted with IPA immediately after and two days after spiking (with refrigerated storage at $\sim 4{ }^{\circ} \mathrm{C}$ ) with $10 \mu \mathrm{g}$ of each CWA. Numbers are the average of triplicate samples plus/minus the standard deviation of the measurements.

\begin{tabular}{|c|c|c|c|c|c|}
\hline & \multicolumn{5}{|c|}{ Amount of each CWA removed from the wipe ( $\boldsymbol{\mu g})$} \\
\hline Time (days) & GB & GD & HD & GF & VX \\
\hline $\mathbf{0}$ & $8.04 \pm 0.34$ & $8.64 \pm 0.41$ & $8.03 \pm 0.37$ & $8.95 \pm 0.43$ & $11.18 \pm 0.59$ \\
\hline $\mathbf{2}$ & $8.34 \pm 0.23$ & $9.06 \pm 0.27$ & $8.23 \pm 0.33$ & $9.34 \pm 0.38$ & $11.32 \pm 0.38$ \\
\hline
\end{tabular}

\subsection{CWA Recoveries from Precleaned Wipes versus Wipes used as Received}

Experiments were performed to compare recoveries of CWAs from precleaned wipes and wipes used as received. Wipes were cleaned by Soxhlet extraction with 25/50/25 Ace/DCM/ EtOAc (the final extraction solvent) prior to spiking with CWAs. In efforts to minimize solvent use, the glass fiber filters were precleaned by placing them in a muffle furnace at $450{ }^{\circ} \mathrm{C}$ for 5 hours to remove any organic contaminants. Both precleaned and "as received" wipes were wetting with a small amount of extraction solvent, spiked with CWAs, and extracted and analyzed as described previously to determine if significant differences in CWA recoveries and interferences were observed. The data obtained are shown in Tables 3 and 4.

In order to obtain data that could be compared to previous studies, ${ }^{11,12}$ all wipes were also spiked with $1 \mu \mathrm{g}$ each of the organophosphorus pesticides malathion and diazinon. These compounds are similar in chemical structure to the CWAs, and, for this reason, are also acceptable CWA simulants.

\footnotetext{
${ }^{11}$ Sampling of Common Pesticides and PCBs from Inert Surfaces, EPA/330/1-90-001, October 1989, B. L. Carr and D. F. Hill, National Enforcement Investigations Center, Denver, CO.

${ }^{12}$ American Healthy Homes Survey: A National Study of Residential Pesticides Measured from Floor Wipes, D. M. Stout II, et. al. Environ. Sci. Technol. 2009, 43, 4294-4300.
} 
Data in Table 3 suggest that most analytes could be recovered from all wipe materials examined. The main exceptions were that VX was poorly recovered from the Whatman 42 paper and that both VX and malathion could not be quantified, because of interferences (i.e. high amounts of co-extracted soluble organic matter), from Gauze 2 when it was used as received. When Gauze 2 was precleaned, VX and malathion could be quantified; see Table 4. However, even with cleaning, recoveries for VX and malathion from Gauze 2 were $>150 \%$. This might be attributed to matrix enhancement effects.

Data in Tables 3 and 4 suggest that for most of the analytes, recoveries from wipes used as received and from precleaned wipes were comparable (i.e. the average recoveries were within the standard deviation of the measurements). Analyte concentrations recovered from uncleaned and precleaned wipes were compared using a Student $t$-test. At a significance level of $\alpha=0.5$, differences in analyte recoveries were observed between precleaned and uncleaned wipes for HD, GF, VX and malathion on Gauze 2. Both VX and malathion also showed statistically significantly higher recoveries from unclean Gauze 1than from Gauze 1 that was precleaned. VX showed a statistically significant higher recovery from unclean GFF than from precleaned GFF. This suggests that most wipes, with the exception of Gauze 2, could be used to sample GB, GD, GF, and HD without being precleaned. However, if needed to sample VX, Gauze 1 should be precleaned before use.

Analyte recoveries for diazinon and malathion were compared to data found in the study by Stout II, et. al. ${ }^{13}$ Recoveries of $0.01 \mu \mathrm{g}, 0.5 \mu \mathrm{g}$, and $0.75 \mu \mathrm{g}$ spikes of diazinon on a rayon surgical sponge (Excilon brand, Tyco Health Care Group, Mansfield, MA) were 62\% 5 5\%, 59\% $\pm 3 \%$, and $72 \% \pm 10 \%$, respectively. Recoveries of $0.01 \mu \mathrm{g}, 0.5 \mu \mathrm{g}$, and $0.75 \mu \mathrm{g}$ spikes of malathion on the same material were $89 \% \pm 15 \%, 62 \% \pm 7 \%$, and $74 \% \pm 11 \%$, respectively. Despite the differences in wipe material used and extraction procedures (Stout II, et. al. used pressurized fluid extraction with DCM), recoveries for these analytes by the different methods were reasonably comparable; the LLNL study showed that recoveries of $1 \mu \mathrm{g}$ diazinon on the precleaned wipes ranged from $96 \%-124 \%$ and recoveries of $1 \mu \mathrm{g}$ malathion on the precleaned wipes ranged from 103\%-176\% (see Table 4). However, LLNL observed some recoveries greater than $100 \%$ for malathion, indicating a possible matrix enhancement that was not noted in the Stout II study. Other literature data for diazinon and malathion are summarized in Table 5.

\footnotetext{
${ }^{13}$ Stout II, et. al. Environ. Sci. Technol. 2009.
} 
Table 3. Recoveries for $1 \mu \mathrm{g}$ each analyte spiked directly on a wetted wipe, used as received, and extracted. Each recovery is the average of triplicate experiments.

\begin{tabular}{|c|c|c|c|c|c|c|c|}
\hline & \multicolumn{7}{|c|}{$\begin{array}{c}\text { CWA Recoveries from Wipes Used as Received } \\
\text { Recovery (\%) } \pm \text { Standard Deviation (n=3) }\end{array}$} \\
\hline Wipe & GB & GD & HD & GF & VX & Diazinon & Malathion \\
\hline GFF & $93 \pm 2$ & $110 \pm 4$ & $93 \pm 2$ & $122 \pm 5$ & $128 \pm 7$ & $114 \pm 4$ & $134 \pm 1$ \\
\hline W42 & $88 \pm 4$ & $100 \pm 4$ & $80 \pm 4$ & $115 \pm 3$ & $28 \pm 6$ & $105 \pm 9$ & $119 \pm 12$ \\
\hline G1 & $95 \pm 3$ & $131 \pm 4$ & $86 \pm 2$ & $149 \pm 7$ & $208 \pm 19$ & $120 \pm 4$ & $158 \pm 6$ \\
\hline G2 & $97 \pm 5$ & $128 \pm 8$ & $110 \pm 6$ & $154 \pm 8$ & interference & $120 \pm 3$ & interference \\
\hline
\end{tabular}

Notes: "GFF" indicates glass fiber filter; "W42" indicates the Whatman 42 filter paper; "G1" and "G2" indicate the Kendall-Curity and Certified Safety gauzes, respectively. "Interference" indicates that a significant interference was present that prevented analyte quantification.

Table 4. Recoveries for $1 \mu \mathrm{g}$ each analyte spiked directly on a precleaned, wetted wipe and extracted. Each recovery is the average of triplicate experiments. The solvent control, which consisted of analytes spiked directly into $30.00 \mathrm{~mL}$ of the final extraction solvent, which was reduced in volume to $1.00 \mathrm{~mL}$ and analyzed after the wipe samples, shows high recoveries for VX and malathion. This observation suggests that matrix enhancement effects are a problem.

\begin{tabular}{|c|c|c|c|c|c|c|c|}
\hline & \multicolumn{7}{|c|}{$\begin{array}{c}\text { CWA Recoveries from Precleaned Wipes } \\
\text { Recovery (\%) } \pm \text { Standard Deviation (n=3) }\end{array}$} \\
\hline Wipe & GB & GD & HD & GF & VX & Diazinon & Malathion \\
\hline GFF & $94 \pm 6$ & $115 \pm 6$ & $97 \pm 6$ & $130 \pm 8$ & $96 \pm 9$ & $114 \pm 6$ & $130 \pm 6$ \\
\hline W42 & $90 \pm 3$ & $105 \pm 6$ & $83 \pm 4$ & $119 \pm 8$ & $33 \pm 4$ & $96 \pm 8$ & $103 \pm 10$ \\
\hline G1 & $94 \pm 6$ & $125 \pm 7$ & $90 \pm 5$ & $142 \pm 9$ & $101 \pm 12$ & $116 \pm 4$ & $146 \pm 5$ \\
\hline G2 & $93 \pm 2$ & $120 \pm 2$ & $100 \pm 2$ & $139 \pm 5$ & $274 \pm 34$ & $124 \pm 2$ & $176 \pm 6$ \\
\hline & & & & & & & \\
\hline $\begin{array}{l}\text { Solvent } \\
\text { Control }\end{array}$ & 96 & 116 & 109 & 133 & 262 & 117 & 274 \\
\hline
\end{tabular}

WipeTask4b_022410pt1_noIS_v01.xls

Notes: "GFF" indicates glass fiber filter; "W42" indicates the Whatman 42 filter paper; "G1" and "G2" indicate the Kendall-Curity and Certified Safety gauzes, respectively. Solvent control represents a single analysis of $1 \mu \mathrm{g}$ each analyte spiked directly into $1.00 \mathrm{~mL}$ of 25/50/25 Ace/DCM/EtOAc. 
Table 5. Data for diazinon and malathion reported in the literature.

\begin{tabular}{|c|c|c|c|c|}
\hline Analyte & Spike Amount & Wipe Solvent & Wipe Material & Recovery (\%) \\
\hline \multirow{4}{*}{ Diazinon $^{\mathrm{a}}$} & \multirow{4}{*}{$\begin{array}{l}375 \mu \mathrm{g} \text { on aluminum } \\
\text { surface }\end{array}$} & isooctane & TLC saturation pad & $70 \pm 7$ \\
\hline & & acetone & TLC saturation pad & $57 \pm 9$ \\
\hline & & isopropanol & TLC saturation pad & $62 \pm 13$ \\
\hline & & dichloromethane & TLC saturation pad & $55 \pm 9$ \\
\hline Diazinon $^{b}$ & $0.75 \mu \mathrm{g}$ on wipe & N/A & rayon surgical sponge & $72 \pm 10$ \\
\hline \multirow{4}{*}{ Malathion $^{\mathrm{a}}$} & \multirow{4}{*}{$\begin{array}{l}1 \mu \mathrm{g} \text { on aluminum } \\
\text { surface }\end{array}$} & isooctane & TLC saturation pad & $80 \pm 5$ \\
\hline & & acetone & TLC saturation pad & $66 \pm 6$ \\
\hline & & isopropanol & TLC saturation pad & $42 \pm 12$ \\
\hline & & dichloromethane & TLC saturation pad & $81 \pm 7$ \\
\hline \multirow{5}{*}{ Malathion $^{\mathrm{a}}$} & \multirow{5}{*}{$\begin{array}{l}\text { unspecified amount } \\
\text { on aluminum surface }\end{array}$} & \multirow{5}{*}{ isooctane } & polyurethane & $53 \pm 13$ \\
\hline & & & cotton balls & $31 \pm 29$ \\
\hline & & & gauze & $64 \pm 14$ \\
\hline & & & TLC saturation pad & $80 \pm 4$ \\
\hline & & & dental wick & $56 \pm 9$ \\
\hline Malathion $^{\mathrm{b}}$ & $0.75 \mu \mathrm{g}$ on wipe & N/A & $\begin{array}{l}\text { rayon microfiber surgical } \\
\text { sponge }\end{array}$ & $74 \pm 11$ \\
\hline
\end{tabular}

Notes: ${ }^{\mathrm{a}}$ Carr and Hill, EPA/330/1-90-001, 1989; ${ }^{\mathrm{b}}$ Stout II, et. al. Environ. Sci. Technol. 2009.

\subsection{Extraction Efficiencies for Various Wipes and Wetting Solvents}

Studies were performed to determine the best combination of wipe and wetting solvent for the collection of CWAs from selected surfaces. Because of the chemical interferences observed in the uncleaned wipes, all wipes were precleaned, as described in Section 3.2, prior to use. Coupons were spiked with $1 \mu \mathrm{g}$ each CWA and pesticide and extracted by using a wipe procedure and by direct extraction. Sets of three coupons were spiked and extracted to produce average data ( $\mathrm{n}=3$ replicates) representing each wetting solvent and extraction condition. Both wipe and direct extractions were performed so that the results of the two extraction methods could be compared. For wipe extractions, different wipe materials were wetted with various solvents prior to sample collection. Each wipe of the same material was wetted with a consistent volume of solvent; however, because the absorbency of each material was different, the amount of solvent required to wet each type of wipe differed. Wipes and coupons were extracted, with 25/50/25 Ace/DCM/EtOAc, and analyzed per the CWA-SAP. The results of solvent extraction were compared with those produced by wipe extraction and are shown in Tables 6-9.

The interpretation of the data presented in Tables 6-9 is not straight-forward because CWA recoveries are affected by both the persistence of the CWA on the surface and the efficiencies with which they are extracted from the surfaces. Past experience in our lab has suggested that GB and HD do not persist on stainless steel or glass surfaces (unpublished data); whether this is due to CWA volatilization or degradation is unclear. Because the glass and 
stainless steel surfaces selected for the experiments are both non-porous and non-permeable, we would expect that all of the CWA present on the surface of the sample coupons should be easily removed by direct solvent extraction (i.e. the "Extraction Control" experiments of Tables 6-9). Thus, recoveries less than $100 \%$ for direct extraction of these surfaces may be suggestive of CWA volatilization or degradation. Comparison of recoveries of the Extraction Control experiments and those provided by the "Solvent Spike Control" (i.e. in which CWAs were spiked directly into $1 \mathrm{~mL}$ of solvent, which represents the volume of the final sample extract) and "Extraction Solvent Spike and Evaporation Control" indicate if CWA losses are occurring during the stage of sample preparation process in which the volume of the sample extract is reduced from $30 \mathrm{~mL}$ to $1 \mathrm{~mL}$. The data shown in Tables 6-9 indicate that significant loses of CWAs (with the possible exception of VX, in some cases) are not occurring during the volume reduction of the sample extracts (comparison of Solvent Spike Control and Extraction Solvent Spike and Evaporation Control recoveries). Thus, we may conclude that, when microgram quantities of CWA are deposited as dilute solutions on glass or stainless steel, GB, GD, HD, and, perhaps, GF are not persistent. Given the previous discussion, the important information to glean from Tables 6-9 are the comparative recoveries of wipe extractions and direct extractions and not the absolute recovery values for the CWAs.

In general, high standard deviations were observed in the triplicate measurements of the wipe samples. The highest standard deviations were noted at times when one of the three replicate samples produced a "non-detectable" result. In general, results of solvent extraction of the surfaces showed higher recoveries than did wipe sampling. Several agents did not persist on either the stainless steel or glass surfaces. Less than $15 \%$ of GB was recovered by wipe sampling from either glass or stainless steel. Recoveries of GB in the extraction controls ranged from not detectable to approximately 50\%. Likewise, GD and HD were not recovered well from metal or glass surfaces by wipe sampling or by direct solvent extraction. The expectation is that these analytes would not persist in the environment at low concentrations on stainless steel or glass surfaces after an incident with chemical agent.

GF, VX, diazinon and malathion were persistent on both the metal and glass surfaces. With consideration given to wipe material, VX was not recovered as well from Whatman 42 filters or from the glass fiber filters as it was from Gauzes 1 and 2. In contrast, GF, diazinon and malathion appeared to be adequately recovered regardless of the wipe material selected. Given the variability in the data, no conclusions could be drawn regarding the selection of wipe solvent. However, it was observed that the more volatile solvents (DCM and Ace/DCM) readily evaporated from the wipes. Thus, operationally, because it is not efficient to wipe a surface with a dry wipe, the less volatile (and, also less aggressive) solvents IPA and hexane, might make the more desirable wipe solvents. Considering that IPA is miscible with water, which might cause concerns for CWA degradation, hexane might be the most appropriate wetting solvent for future wipe experiments. 
Table 6. Recoveries of $1 \mu \mathrm{g}$ each CWA and pesticide sampled from glass or metal surfaces using Gauze 1 and various wipe solvents. Wipe solvents tested included DCM, 50/50 (v/v) 50/50 Ace/DCM, IPA, and hexane. Each recovery is the average of three replicate sample

preparations/analyses and is reported as a percent plus/minus the standard deviation of the measurements. Extraction controls consisted of $1 \mu \mathrm{g}$ each CWA and pesticide spiked directly on the surface and extracted with a solvent. Solvent spike controls consisted of $1 \mu \mathrm{g}$ each CWA and pesticide spiked directly into $1.00 \mathrm{~mL}$ of DCM. Extraction solvent spike and evaporation controls consisted of $1 \mu \mathrm{g}$ each CWA and pesticide spiked directly into $30.00 \mathrm{~mL}$ of the extraction solvent, which was then evaporated to a volume of $1.00 \mathrm{~mL}$. Recoveries reported for all control samples represent a single analysis.

\begin{tabular}{|c|c|c|c|c|c|c|c|}
\hline & \multicolumn{7}{|c|}{ Recoveries (\%) of $1 \mu \mathrm{g}$ each agent; wipe material is Gauze 1} \\
\hline & \multicolumn{7}{|c|}{ From Glass Surface } \\
\hline Wipe Solvent & GB & GD & HD & GF & $\mathbf{V X}$ & diazinon & malathion \\
\hline DCM & not detected & $1 \pm 2$ & $14 \pm 5$ & $35 \pm 11$ & $83 \pm 12$ & $130 \pm 8$ & $158 \pm 9$ \\
\hline 50/50 Ace/DCM & $2 \pm 2$ & $16 \pm 8$ & $32 \pm 12$ & $68 \pm 16$ & $118 \pm 15$ & $144 \pm 8$ & $182 \pm 13$ \\
\hline IPA & $4 \pm 5$ & $23 \pm 10$ & $37 \pm 7$ & $75 \pm 12$ & $227 \pm 140$ & $195 \pm 93$ & $257 \pm 127$ \\
\hline Hexane & $14 \pm 9$ & $43 \pm 8$ & $43 \pm 9$ & $86 \pm 6$ & $145 \pm 4$ & $152 \pm 4$ & $199 \pm 5$ \\
\hline Extraction Control & 10 & 24 & 38 & 53 & 103 & 131 & 143 \\
\hline Solvent Spike Control & 130 & 140 & 127 & 146 & 71 & 159 & 178 \\
\hline $\begin{array}{l}\text { Extraction Solvent Spike + } \\
\text { Evaporation Control }\end{array}$ & 112 & 126 & 106 & 138 & 41 & 144 & 163 \\
\hline & \multicolumn{7}{|c|}{ From Stainless Steel Surface } \\
\hline Wipe Solvent & GB & GD & HD & GF & $\mathbf{V X}$ & diazinon & malathion \\
\hline $\mathrm{DCM}$ & not detected & $6 \pm 3$ & $19 \pm 4$ & $54 \pm 4$ & $129 \pm 3$ & $146 \pm 6$ & $188 \pm 6$ \\
\hline 50/50 Ace/DCM & not detected & $4 \pm 1$ & $21 \pm 4$ & $58 \pm 8$ & $158 \pm 15$ & $156 \pm 10$ & $202 \pm 14$ \\
\hline IPA & not detected & $4 \pm 3$ & $21 \pm 11$ & $54 \pm 18$ & $172 \pm 11$ & $153 \pm 6$ & $202 \pm 7$ \\
\hline Hexane & not detected & $8 \pm 6$ & $21 \pm 6$ & $58 \pm 9$ & $128 \pm 20$ & $154 \pm 7$ & $205 \pm 8$ \\
\hline Extraction Control & 2 & 8 & 2 & 23 & 73 & 122 & 131 \\
\hline Solvent Control & 130 & 140 & 127 & 146 & 71 & 159 & 178 \\
\hline $\begin{array}{l}\text { Extraction Solvent Spike + } \\
\text { Evaporation Control }\end{array}$ & 112 & 126 & 106 & 138 & 41 & 144 & 163 \\
\hline
\end{tabular}


Table 7. Recoveries of $1 \mu \mathrm{g}$ each CWA and pesticide sampled from glass or metal surfaces using Gauze 2 and various wipe solvents. Wipe solvents tested included DCM, 50/50 (v/v) Ace/DCM, IPA, and hexane. Each recovery is the average of three replicate sample

preparations/analyses and is reported as a percent plus/minus the standard deviation of the measurements. Extraction controls consisted of $1 \mu \mathrm{g}$ each CWA and pesticide spiked directly on the surface and extracted with a solvent. Solvent spike controls consisted of $1 \mu \mathrm{g}$ each CWA and pesticide spiked directly into $1.00 \mathrm{~mL}$ of DCM. Extraction solvent spike and evaporation controls consisted of $1 \mu \mathrm{g}$ each CWA and pesticide spiked directly into $30.00 \mathrm{~mL}$ of the extraction solvent, which was then evaporated to a volume of $1.00 \mathrm{~mL}$. Recoveries reported for all control samples represent a single analysis.

\begin{tabular}{|c|c|c|c|c|c|c|c|}
\hline & \multicolumn{7}{|c|}{ Recoveries (\%) of $1 \mu \mathrm{g}$ each agent; wipe material is Gauze 2} \\
\hline & \multicolumn{7}{|c|}{ From Glass Surface } \\
\hline Wipe Solvent & GB & GD & HD & GF & VX & diazinon & malathion \\
\hline DCM & $15 \pm 15$ & $24 \pm 11$ & $33 \pm 22$ & $51 \pm 24$ & $77 \pm 8$ & $129 \pm 10$ & $158 \pm 4$ \\
\hline 50/50 Ace/DCM & $9 \pm 10$ & $20 \pm 9$ & $27 \pm 23$ & $42 \pm 35$ & $56 \pm 48$ & $90 \pm 73$ & $112 \pm 90$ \\
\hline IPA & $4 \pm 5$ & $17 \pm 7$ & $33 \pm 19$ & $60 \pm 28$ & $168 \pm 99$ & $174 \pm 66$ & $218 \pm 82$ \\
\hline Hexane & $5 \pm 8$ & $14 \pm 11$ & $26 \pm 25$ & $49 \pm 35$ & $144 \pm 96$ & $172 \pm 76$ & $213 \pm 98$ \\
\hline Extraction Control & 56 & 35 & 67 & 88 & 134 & 129 & 150 \\
\hline Solvent Spike Control & 136 & 159 & 128 & 166 & 124 & 171 & 209 \\
\hline $\begin{array}{l}\text { Extraction Solvent Spike + } \\
\text { Evaporation Control }\end{array}$ & 110 & 132 & 105 & 145 & 64 & 148 & 178 \\
\hline & \multicolumn{7}{|c|}{ From Stainless Steel Surface } \\
\hline Wipe Solvent & GB & GD & HD & GF & VX & diazinon & malathion \\
\hline DCM & not detected & $2 \pm 0$ & $4 \pm 3$ & $18 \pm 8$ & $82 \pm 34$ & $123 \pm 35$ & $150 \pm 44$ \\
\hline 50/50 Ace/DCM & not detected & $5 \pm 3$ & $10 \pm 14$ & $31 \pm 23$ & $117 \pm 3$ & $146 \pm 6$ & $180 \pm 5$ \\
\hline IPA & not detected & not detected & $3 \pm 1$ & $13 \pm 3$ & $98 \pm 25$ & $130 \pm 16$ & $161 \pm 21$ \\
\hline Hexane & $1 \pm 1$ & $8 \pm 6$ & $16 \pm 19$ & $39 \pm 26$ & $92 \pm 7$ & $150 \pm 9$ & $189 \pm 13$ \\
\hline Extraction Control & 3 & 10 & 22 & 47 & 156 & 143 & 166 \\
\hline Solvent Spike Control & 136 & 159 & 128 & 166 & 124 & 171 & 209 \\
\hline $\begin{array}{l}\text { Extraction Solvent Spike + } \\
\text { Evaporation Control }\end{array}$ & 110 & 132 & 105 & 145 & 64 & 148 & 178 \\
\hline
\end{tabular}


Table 8. Recoveries of $1 \mu \mathrm{g}$ each CWA and pesticide sampled from glass or metal surfaces using Whatman 42 filters and various wipe solvents. Wipe solvents tested included DCM, 50/50 (v/v) Ace/DCM, IPA, and hexane. Each recovery is the average of three replicate sample preparations/analyses and is reported as a percent plus/minus the standard deviation of the measurements. Extraction controls consisted of $1 \mu \mathrm{g}$ each CWA and pesticide spiked directly on the surface and extracted with a solvent. Solvent spike controls consisted of $1 \mu \mathrm{g}$ each CWA and pesticide spiked directly into $1.00 \mathrm{~mL}$ of DCM. Extraction solvent spike and evaporation controls consisted of $1 \mu \mathrm{g}$ each CWA and pesticide spiked directly into $30.00 \mathrm{~mL}$ of the extraction solvent, which was then evaporated to a volume of $1.00 \mathrm{~mL}$. Recoveries reported for all control samples represent a single analysis.

\begin{tabular}{|c|c|c|c|c|c|c|c|}
\hline & \multicolumn{7}{|c|}{ Recoveries (\%) of $1 \mu$ g each agent; wipe material is Whatman 42 Filter } \\
\hline & \multicolumn{7}{|c|}{ From Glass Surface } \\
\hline Wipe Solvent & GB & GD & HD & GF & $\mathbf{V X}$ & diazinon & malathion \\
\hline DCM & not detected & $4 \pm 1$ & $12 \pm 3$ & $30 \pm 6$ & $26 \pm 5$ & $118 \pm 13$ & $140 \pm 14$ \\
\hline 50/50 Ace/DCM & $8 \pm 14$ & $19 \pm 10$ & $24 \pm 15$ & $52 \pm 20$ & $21 \pm 4$ & $131 \pm 19$ & $154 \pm 26$ \\
\hline IPA & $7 \pm 7$ & $20 \pm 8$ & $21 \pm 13$ & $44 \pm 23$ & $15 \pm 9$ & $104 \pm 36$ & $123 \pm 50$ \\
\hline Hexane & not detected & $8 \pm 3$ & $15 \pm 3$ & $48 \pm 8$ & $23 \pm 6$ & $131 \pm 11$ & $159 \pm 15$ \\
\hline Extraction Control & not detected & 2 & 9 & 26 & 102 & 148 & 175 \\
\hline Solvent Spike Control & 128 & 142 & 125 & 150 & 65 & 159 & 183 \\
\hline $\begin{array}{l}\text { Extraction Solvent Spike + } \\
\text { Evaporation Control }\end{array}$ & 106 & 128 & 102 & 138 & 50 & 148 & 175 \\
\hline & \multicolumn{7}{|c|}{ From Stainless Steel Surface } \\
\hline Wipe Solvent & GB & GD & HD & GF & VX & diazinon & malathion \\
\hline DCM & not detected & $7 \pm 1$ & $18 \pm 2$ & $41 \pm 4$ & $36 \pm 4$ & $139 \pm 9$ & $172 \pm 17$ \\
\hline 50/50 Ace/DCM & not detected & $8 \pm 3$ & $19 \pm 11$ & $43 \pm 11$ & $32 \pm 9$ & $147 \pm 6$ & $185 \pm 11$ \\
\hline IPA & not detected & $3 \pm 1$ & $10 \pm 6$ & $29 \pm 12$ & $37 \pm 13$ & $132 \pm 6$ & $166 \pm 7$ \\
\hline Hexane & not detected & $3 \pm 2$ & $10 \pm 7$ & $33 \pm 16$ & $25 \pm 2$ & $146 \pm 1$ & $192 \pm 5$ \\
\hline Extraction Control & not detected & 1 & 9 & 27 & 79 & 147 & 180 \\
\hline Solvent Spike Control & 128 & 142 & 125 & 150 & 65 & 159 & 183 \\
\hline $\begin{array}{l}\text { Extraction Solvent Spike + } \\
\text { Evaporation Control }\end{array}$ & 106 & 128 & 102 & 138 & 50 & 147 & 175 \\
\hline
\end{tabular}


Table 9. Recoveries of $1 \mu \mathrm{g}$ each CWA and pesticide sampled from glass or metal surfaces using glass fiber filters and various wipe solvents. Wipe solvents tested included DCM, 50/50 (v/v) Ace/DCM, IPA, and hexane. Each recovery is the average of three replicate sample preparations/analyses and is reported as a percent plus/minus the standard deviation of the measurements. Extraction controls consisted of $1 \mu \mathrm{g}$ each CWA and pesticide spiked directly on the surface and extracted with a solvent. Solvent spike controls consisted of $1 \mu \mathrm{g}$ each CWA and pesticide spiked directly into $1.00 \mathrm{~mL}$ of DCM. Extraction solvent spike and evaporation controls consisted of $1 \mu \mathrm{g}$ each CWA and pesticide spiked directly into $30.00 \mathrm{~mL}$ of the extraction solvent, which was then evaporated to a volume of $1.00 \mathrm{~mL}$. Recoveries reported for all control samples represent a single analysis.

\begin{tabular}{|c|c|c|c|c|c|c|c|}
\hline & \multicolumn{7}{|c|}{ Recoveries (\%) of $1 \mu \mathrm{g}$ each agent; wipe material is Glass Fiber Filter } \\
\hline & \multicolumn{7}{|c|}{ From Glass Surface } \\
\hline Wipe Solvent & GB & GD & HD & GF & VX & diazinon & malathion \\
\hline DCM & $5 \pm 8$ & $14 \pm 8$ & $20 \pm 13$ & $42 \pm 19$ & $41 \pm 7$ & $111 \pm 16$ & $117 \pm 16$ \\
\hline 50/50 Ace/DCM & $7 \pm 12$ & $22 \pm 8$ & $31 \pm 8$ & $53 \pm 8$ & $35 \pm 5$ & $120 \pm 7$ & $125 \pm 7$ \\
\hline IPA & $7 \pm 7$ & $19 \pm 7$ & $28 \pm 8$ & $49 \pm 7$ & $50 \pm 5$ & $111 \pm 4$ & $137 \pm 9$ \\
\hline Hexane & $4 \pm 4$ & $16 \pm 6$ & $24 \pm 12$ & $45 \pm 17$ & $38 \pm 2$ & $123 \pm 11$ & $148 \pm 13$ \\
\hline Extraction Control & 53 & 71 & 73 & 88 & 91 & 119 & 92 \\
\hline Solvent Spike Control & 115 & 128 & 129 & 127 & 60 & 121 & 89 \\
\hline $\begin{array}{l}\text { Extraction Solvent Spike + } \\
\text { Evaporation Control }\end{array}$ & 98 & 113 & 101 & 113 & 37 & 111 & 84 \\
\hline & \multicolumn{7}{|c|}{ From Stainless Steel Surface } \\
\hline Wipe Solvent & GB & GD & HD & GF & VX & diazinon & malathion \\
\hline DCM & not detected & $3 \pm 1$ & $11 \pm 8$ & $26 \pm 10$ & $37 \pm 6$ & $126 \pm 2$ & $144 \pm 5$ \\
\hline 50/50 Ace/DCM & not detected & $2 \pm 1$ & $6 \pm 5$ & $18 \pm 12$ & $34 \pm 7$ & $120 \pm 6$ & $143 \pm 5$ \\
\hline IPA & not detected & $4 \pm 1$ & $17 \pm 4$ & $37 \pm 6$ & $60 \pm 1$ & $133 \pm 11$ & $169 \pm 12$ \\
\hline Hexane & not detected & $1 \pm 1$ & $5 \pm 6$ & $16 \pm 13$ & $33 \pm 11$ & $137 \pm 7$ & $175 \pm 11$ \\
\hline Extraction Control & 53 & 67 & 63 & 79 & 116 & 165 & not detected \\
\hline Solvent Spike Control & 115 & 128 & 129 & 127 & 60 & 121 & 89 \\
\hline $\begin{array}{l}\text { Extraction Solvent Spike + } \\
\text { Evaporation Control }\end{array}$ & 98 & 113 & 101 & 113 & 37 & 111 & 84 \\
\hline
\end{tabular}




\subsection{Sample Holding Times for CWAs on Selected Wipes}

As both Gauze 1 and the glass fiber filters were deemed the most useful wipe materials, considering their cleanliness (e.g. their ability to be easily precleaned), their structural integrities, and their ability to retain wetting solvent, these materials were spiked with CWA and pesticides $(0.1 \mu \mathrm{g}$ and $1 \mu \mathrm{g}$ levels $)$, stored in a refrigerator $\left(\sim 4^{\circ} \mathrm{C}\right)$, and extracted and analyzed at various times over the course of a month to establish sample holding time. Gauze 1 was selected as a good wipe material because of its structural integrity during the wiping process, because this type of wipe material is often used for wipe sampling, and previous data showed that the material could be easily cleaned to remove wipe contaminants. While the structural integrity of the glass fiber filter was not as good as that of Gauze 1, the ease with which this material could be precleaned by placing it in a muffle furnace was a sufficiently desirable trait that warranted its inclusion in the holding time study. Holding time studies were not performed on Gauze 2 because this material, even cleaned, showed significantly more interferences than did Gauze 1. The Whatman 42 filter paper was not studied because it showed poor recoveries for VX and did not retain wetting solvent (i.e. the material dried quickly after wetting).

The results of the holding time studies are shown in Figures 6 and 7. Figure 6 shows the results obtained when the CWAs were spiked on glass fiber filters. Figure 6 shows that VX, at spike levels of $1 \mu \mathrm{g}$ and $0.1 \mu \mathrm{g}$ per glass fiber filter could not be detected after 2 days. It is unclear if this is caused by VX degradation or by irreversible adsorption of VX onto the glass fiber filters. It was noted in a previous study that VX degrades on glass and sand surfaces. ${ }^{14}$ $\mathrm{GB}$, at $0.1 \mu \mathrm{g}$ per wipe, could not be detected on the glass fiber filter at any of the time points tested. Because it has been observed that GB, at low concentrations, rapidly volatilizes, it is suspected that volatilization from the wipes might be the cause of nonexistent GB recoveries. However, GB at the $1 \mu \mathrm{g}$ spike level could be detected after 14 days with no significant losses (>80\%) of material observed. And, GB was still present on the wipes after 30 days. With the exception of VX, and GB at low concentrations, all other CWAs (GD, GF, and HD), at both $1 \mu \mathrm{g}$ and $0.1 \mu \mathrm{g}$ spike levels, were stable for 7 days on the glass fiber filters. After 14 days, GD, GF, and HD were clearly present in the samples, but their concentrations were $\sim 20 \%$ lower than at the start of the experiment. By comparison, $1 \mu \mathrm{g}$ spikes of both diazinon and malathion (data not plotted) were stable for the 30 day course of the experiment.

Figure 7 shows the results obtained when the CWAs were spiked on Gauze 1. Note that, at spike levels of $0.1 \mu \mathrm{g}$ per wipe, no GB was recovered at any time point from Gauze 1. This is consistent with the results of experiments with $0.1 \mu \mathrm{g}$ GB on the glass fiber filters (see Figure 6). For all of the CWAs spiked at $1 \mu \mathrm{g}$ per wipe (with the exception of some anomalous VX points), the CWAs appeared to be stable over the course of a month on Gauze 1. At $0.1 \mu \mathrm{g}$, all agents, with the exception of GB, were still detected at 30 days.

\footnotetext{
${ }^{14}$ Evaporation and Degradation of VX on Silica Sand, C. A. S. Brevett, K. B. Sumpter, J. Pence, R. G. Nickol, B. E.
} King, C. V. Giannaras, H. D. Durst, J. Phys. Chem. 2009, 113, 6622-6633. 


\section{Holding Time Study - Glass Fiber Filter, 1 mg spike}

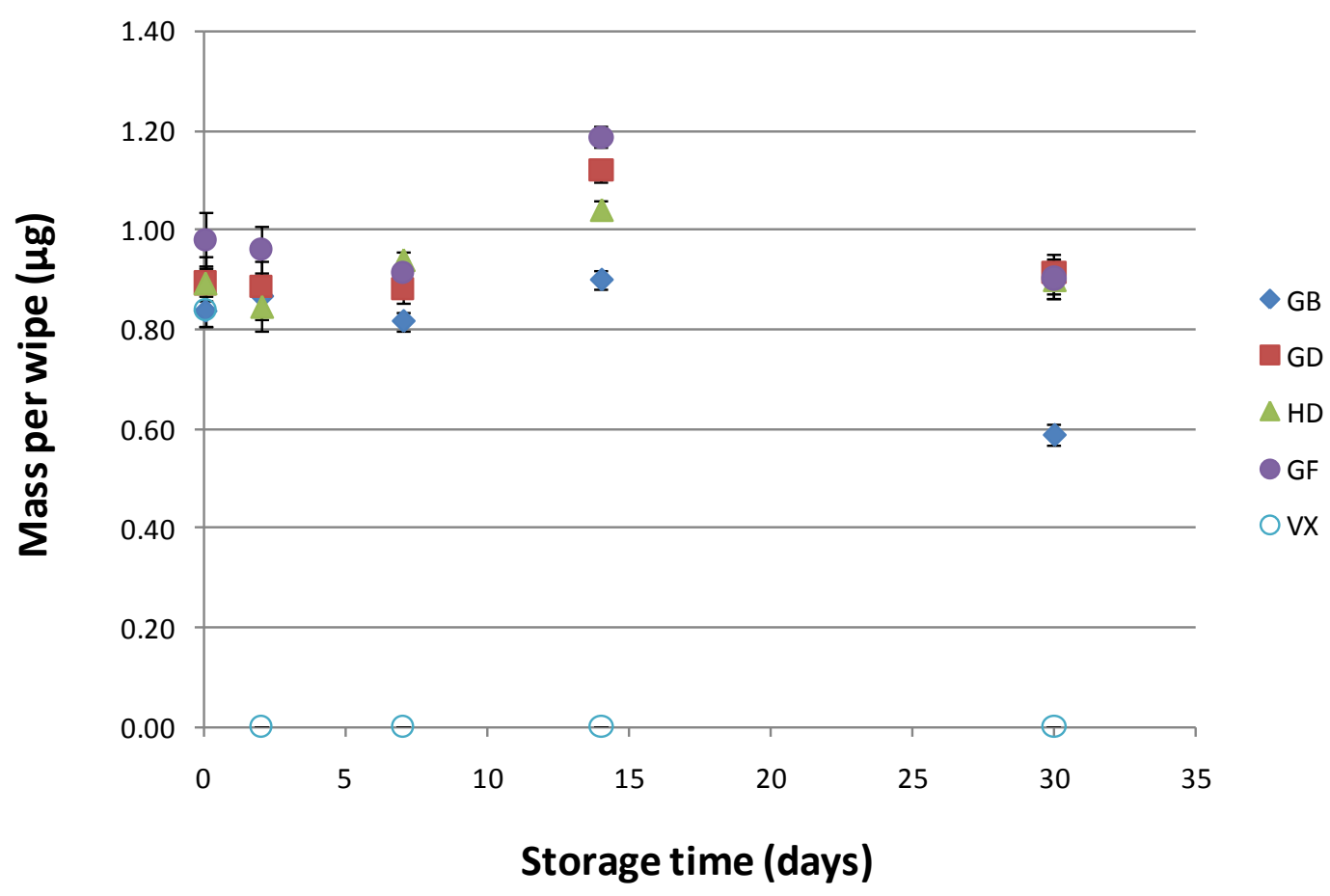

\section{Holding Time Study - Glass Fiber Filter, $0.1 \mu \mathrm{g}$ spike}

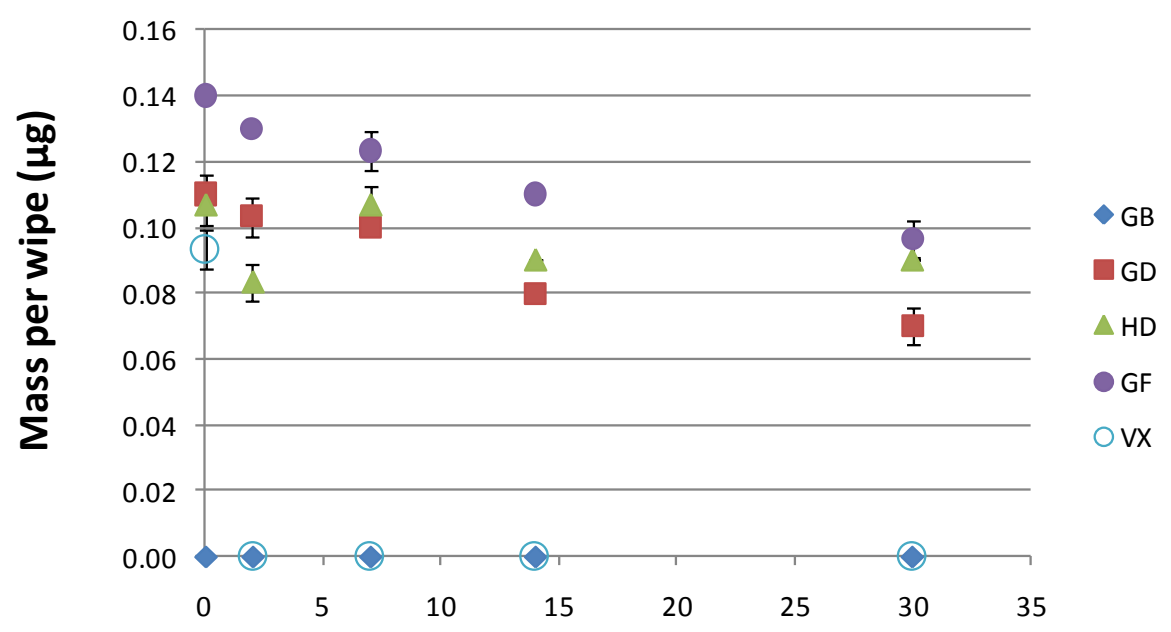

\section{Storage time (days)}

Figure 6. Plots of mass of CWA remaining on glass fiber filters as a function of refrigerated $\left(\sim 4{ }^{\circ} \mathrm{C}\right)$ storage time when $1 \mu \mathrm{g}$ each CWA (top) and $0.1 \mu \mathrm{g}$ each CWA (bottom) were spiked directly on the DCM-wetted wipe. Error bars represent the standard deviation of three, replicate analyses of the wipes. 


\section{Holding Time Study - Gauze 1, 1 rg spike}

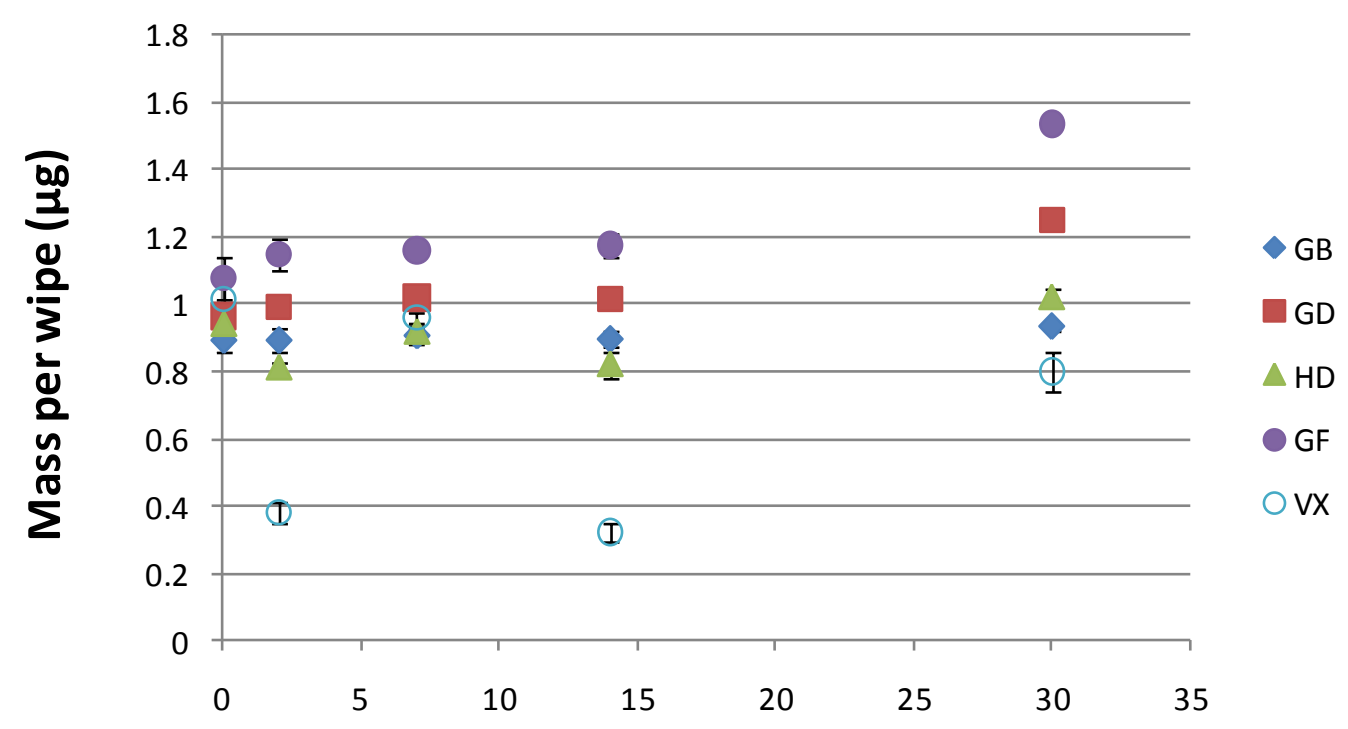

Storage time (days)

Holding Time Study - Gauze 1, $0.1 \mu \mathrm{g}$ spike

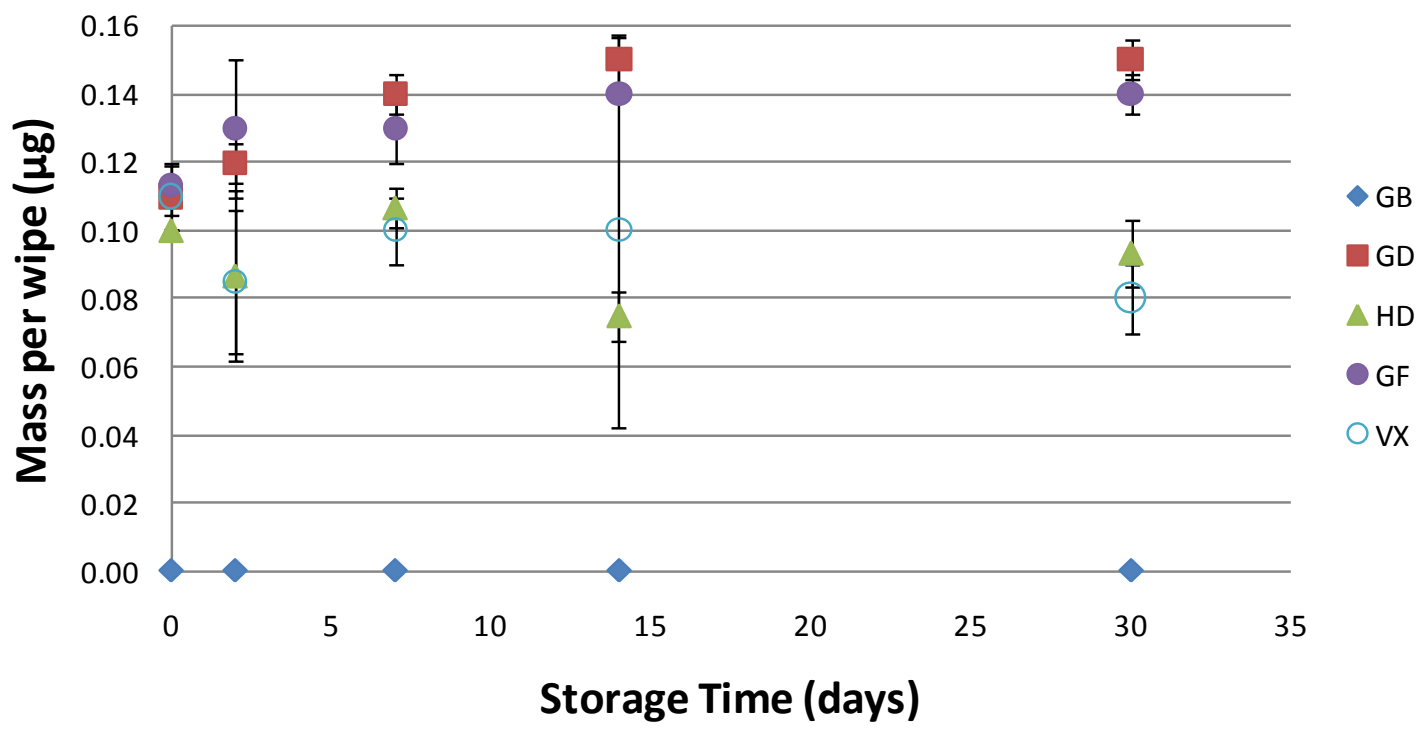

Figure 7. Plots of mass of CWA remaining on Gauze 1 as a function of refrigerated $\left(\sim 4{ }^{\circ} \mathrm{C}\right)$ storage time when $1 \mu \mathrm{g}$ each CWA (top) and $0.1 \mu \mathrm{g}$ each CWA (bottom) were spiked directly on the DCM-wetted wipe. Error bars represent the standard deviation of three, replicate analyses of the wipes. The large error bars for HD on Day 2 at the $0.1 \mu \mathrm{g}$ spike level were attributed to one low data point (masses of HD remaining on the three wipes measured as $0.11,0.09$, and $0.06 \mu \mathrm{g}$ ) and the large error bars for VX on Day 14 at the $0.1 \mu \mathrm{g}$ spike level were attributed to two "non-detects" (masses of VX remaining on the three wipes measured as $0.10,0.0$, and $0.0 \mu \mathrm{g}$ ). 
Given the results shown in Figures 6 and 7, and considering that the detection of the lowest possible concentrations of CWAs is expected to be of importance, it is recommended that samples to be tested for CWAs be analyzed, or at least extracted, within a week of collection so that their measured concentrations will be within $\sim 80 \%$ of their original values. However, depending on the analyte, holding times of 14 days may also be acceptable.

\subsection{Conclusions and Recommendations}

One objective of this study was to investigate wipe materials and wetting solvents. The wipe materials included two cotton gauzes - Gauze 1 (Kendall-Curity) and Gauze 2 (Certified Safety), a glass fiber filter, and a cellulose fiber filter (Whatman 42). Figures of merit for each wipe material are summarized in Table 10. Of the materials examined, Gauze 1 was found to be the most universally acceptable material. Gauze 2 was less desirable because it was found to contain a greater amount of potential interferences and it was difficult to clean. Because Gauze 2 absorbed much of the extraction solvent (and to a greater extent than did Gauze 1), it was more difficult to transfer the Gauze 2 sample extract from the extraction vial into a clean vial than for any of the other wipe materials tested. The Whatman 42 fiber filter did not retain the wetting solvent and poorly recovered VX. While easy-to-clean, the glass fiber filter was reasonably useful; however, it did not retain as much wetting solvent during sampling as did the cotton gauzes. Precleaning of all materials tested prior to sampling is recommended.

Wetting solvents studied included DCM, Ace/DCM, Ace/DCM/EtOAc, IPA, and hexane. Given the scatter in our data, a clear "best solvent" could not be identified. From an operational perspective, and because these solvents are the least prone to evaporation, IPA and hexane were preferred as wetting solvents. Hexane, because it is a relatively dry solvent (unlike IPA which is miscible with water, which has the potential to cause degradation of some of the CWAs), was slightly preferred as the wetting solvent.

Another study goal was to determine the length of time for which CWAs spiked on wetted wipes are stable. Data suggest that a sample holding time of one to two weeks for samples containing CWAs might be appropriate for Gauze 1 and for the glass fiber filter (with the exception that VX cannot be sampled with the glass fiber filter).

Given the results obtained in this study, we recommend that future studies be performed with Gauze 1 and with the glass fiber filters. Specific issues to be studied might include:

- Studies of wipe extraction efficiencies from other surfaces should be performed. In such studies, a smaller subset of wetting solvents (e.g. DCM versus hexane) could be compared. And, experiments comparing wipe extraction and direct solvent extraction should be completed. 
- Studies using larger wipe areas (e.g. $100 \mathrm{~cm}^{2}$ coupons) should be conducted.

- Glass fiber filters that are larger in size than the $47 \mathrm{~mm}$ ones used in this study should be examined to determine if they would better retain wetting solvents.

- Experiments to understand why VX is not recovered from glass fiber filters should be performed.

Knowledge about the efficiencies and limitations of wipe sampling is critical in order to correctly interpret and use the results of the data that wipe sampling provides. Before wipe sampling is performed at a site, it is essential to understand the questions that are to be addressed by sampling efforts and to establish, early-on, that the results produced by wipe sampling will be adequate to answer those questions. The results of a wipe sampling campaign can only be interpreted in the context of meeting preselected study objective(s) and with an understanding that the agent of interest might still reside, in significant quantities, under the surface of the material sampled by wiping. With the exception of non-porous, non-permeable surfaces (e.g. stainless steel, glass, etc.), a "non-detect" produced by wipe sampling cannot be equated with no CWA in a material. This fact must not be forgotten when interpreting the results produced by wipe sampling. 
Table 10. Summary of merits of each wipe material. Note that "+" indicates acceptable; "++" indicates more acceptable; "-“" indicates not acceptable; "“- -" indicates strongly not acceptable. Choice of wipe will depend on the analyte of interest and the sampling scenario.

\begin{tabular}{|c|c|c|c|c|}
\hline Figure of Merit & Gauze 1 & Gauze 2 & Whatman 42 & GFF \\
\hline $\begin{array}{l}\text { Background } \\
\text { contamination }\end{array}$ & - & -- & - & + \\
\hline $\begin{array}{l}\text { Interferences with } \\
\text { CWA analytes if no } \\
\text { cleaning }\end{array}$ & - & -- & + & + \\
\hline Ease of cleaning & + & - & + & ++ \\
\hline $\begin{array}{l}\text { Background after } \\
\text { cleaning }\end{array}$ & + & - & + & ++ \\
\hline $\begin{array}{l}\text { Durability of wipe } \\
\text { during sampling }\end{array}$ & + & ++ & - & -- \\
\hline \multicolumn{5}{|l|}{$\begin{array}{l}\text { Acceptable recovery of } \\
\text { spiked analytes }\end{array}$} \\
\hline GB & + & + & + & + \\
\hline GD & + & + & + & + \\
\hline HD & + & + & + & + \\
\hline GF & $\begin{array}{c}+ \\
\text { Some matrix } \\
\text { enhancements }\end{array}$ & $\begin{array}{c}+ \\
\text { Some matrix } \\
\text { enhancements }\end{array}$ & + & + \\
\hline VX & $\begin{array}{c}+ \\
\text { Some matrix } \\
\text { enhancements }\end{array}$ & $\begin{array}{c}\text { Some matrix } \\
\text { enhancements; } \\
\text { Must preclean } \\
\text { before use because } \\
\text { of interferences }\end{array}$ & -- & -- \\
\hline Malathion & $\begin{array}{c}+ \\
\text { Some matrix } \\
\text { enhancements }\end{array}$ & $\begin{array}{c}\text { Some matrix } \\
\text { enhancements; } \\
\text { Must preclean } \\
\text { before use because } \\
\text { of interferences }\end{array}$ & + & + \\
\hline Diazinon & + & + & + & + \\
\hline
\end{tabular}




\section{Appendix A}

Total ion chromatograms produced when various wipe materials were extracted with different solvents. 

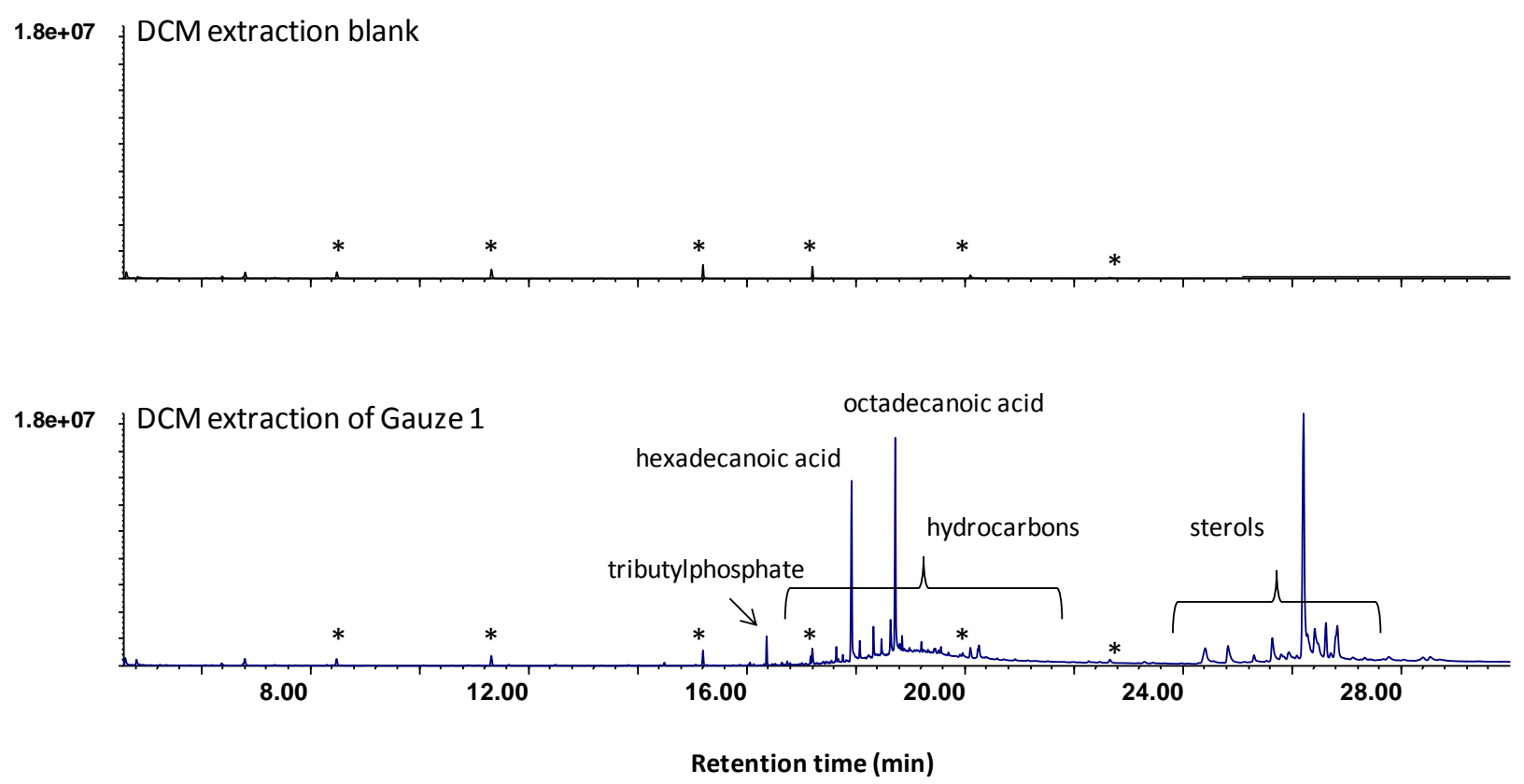

Figure A-1. Total ion chromatogram produced when Gauze 1was extracted with dichloromethane (DCM). Note that "** indicate $1 \mu \mathrm{g}$ each of internal standards that were added to the final sample extract (volume of $1 \mathrm{~mL}$ ) prior to analysis. Internal standards, in order of increasing retention time were 1,4dichlorobenzene- $\mathrm{d}_{4}$, naphthalene- $\mathrm{d}_{8}$, acenaphthene- $\mathrm{d}_{10}$, phenanthrene- $\mathrm{d}_{10}$, chrysene- $\mathrm{d}_{12}$, and perylene- $\mathrm{d}_{12}$. 

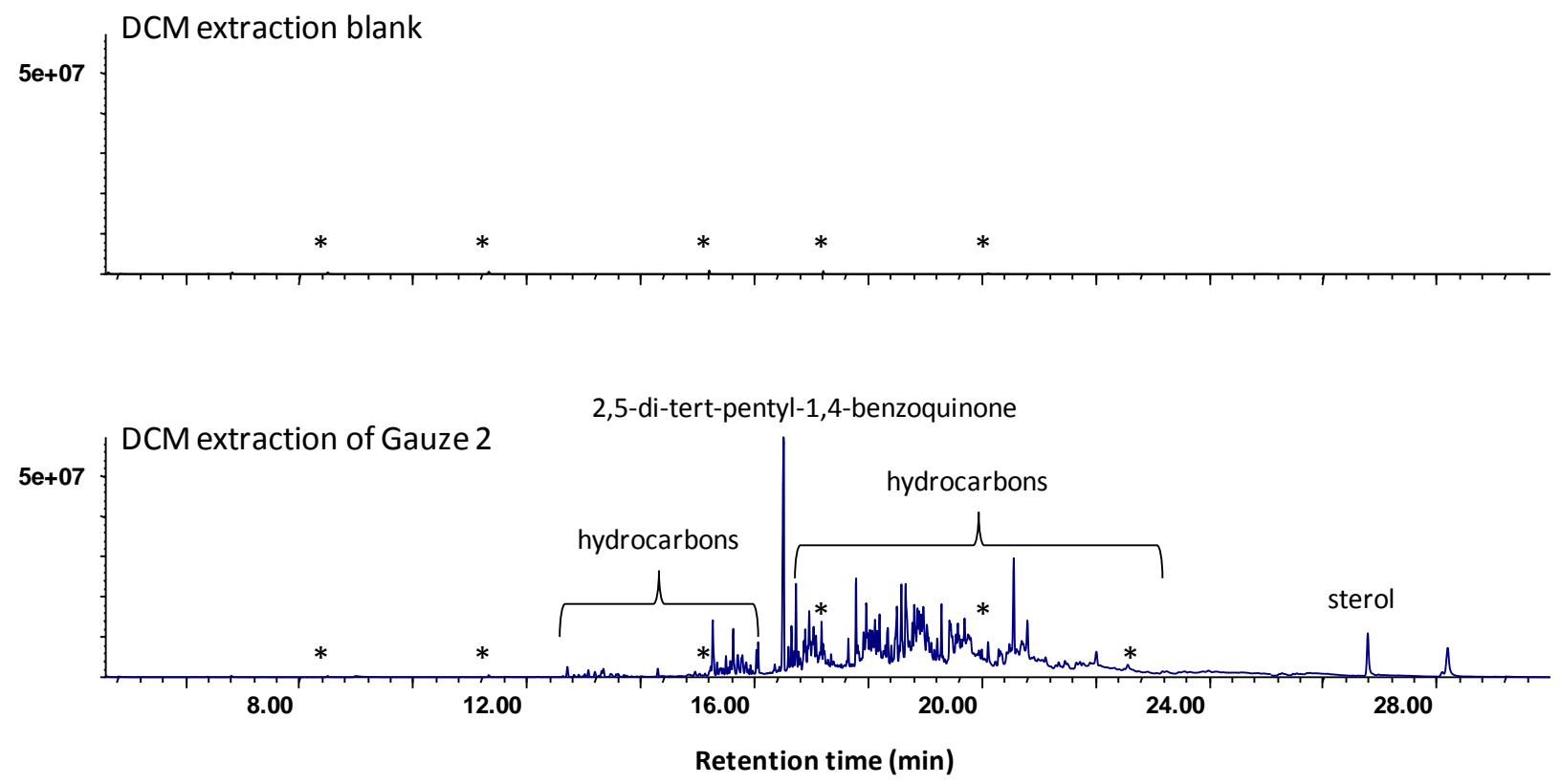

Figure A-2. Total ion chromatogram produced when Gauze 2 was extracted with dichloromethane (DCM). Note that "*" indicate $1 \mu \mathrm{g}$ each of internal standards that were added to the final sample extract (volume of $1 \mathrm{~mL}$ ) prior to analysis. Internal standards, in order of increasing retention time were 1,4dichlorobenzene- $\mathrm{d}_{4}$, naphthalene- $\mathrm{d}_{8}$, acenaphthene- $\mathrm{d}_{10}$, phenanthrene- $\mathrm{d}_{10}$, chrysene- $\mathrm{d}_{12}$, and perylene- $\mathrm{d}_{12}$. 

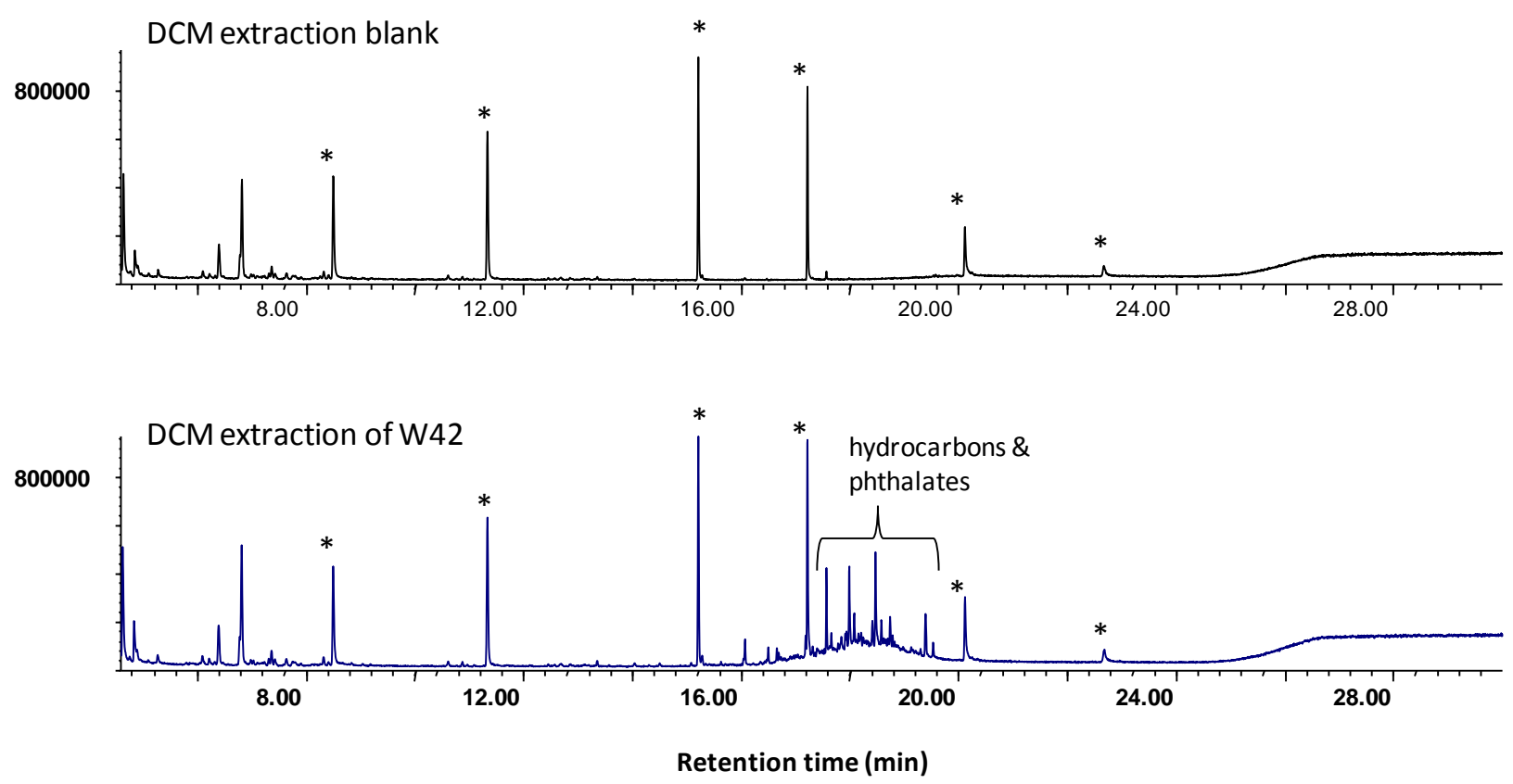

Figure A-3. Total ion chromatogram produced when Whatman 42 filter paper was extracted with dichloromethane (DCM). Note that "*” indicate $1 \mu \mathrm{g}$ each of internal standards that were added to the final sample extract (volume of $1 \mathrm{~mL}$ ) prior to analysis. Internal standards, in order of increasing retention time were 1,4-dichlorobenzene- $\mathrm{d}_{4}$, naphthalene- $\mathrm{d}_{8}$, acenaphthene- $\mathrm{d}_{10}$, phenanthrene- $\mathrm{d}_{10}$, chrysene- $\mathrm{d}_{12}$, and perylene- $\mathrm{d}_{12}$. 

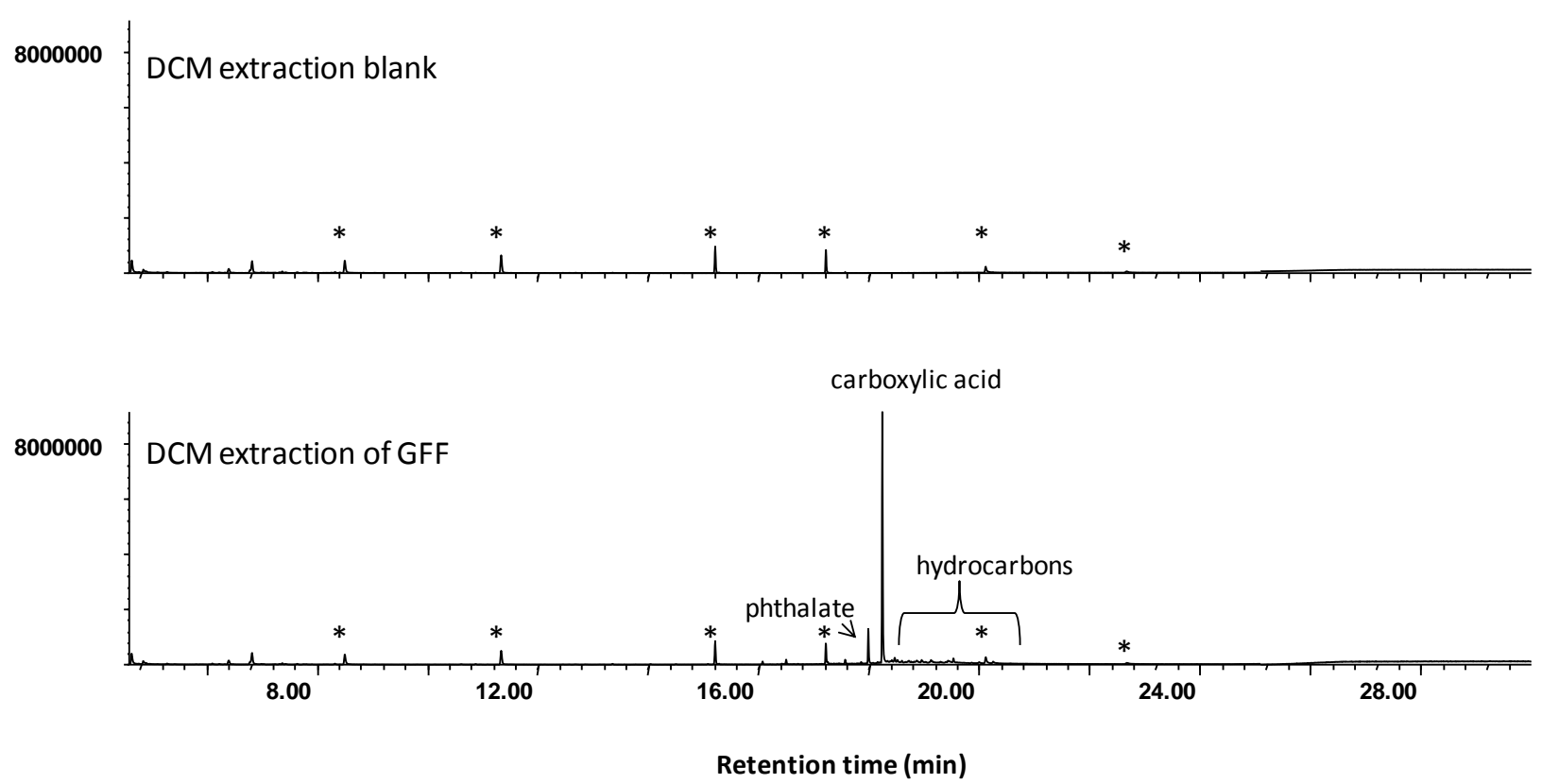

Figure A-4. Total ion chromatogram produced when a glass fiber filter was extracted with dichloromethane (DCM). Note that "*” indicate $1 \mu \mathrm{g}$ each of internal standards that were added to the final sample extract (volume of $1 \mathrm{~mL}$ ) prior to analysis. Internal standards, in order of increasing retention time were 1,4-dichlorobenzene- $\mathrm{d}_{4}$, naphthalene- $\mathrm{d}_{8}$, acenaphthene- $\mathrm{d}_{10}$, phenanthrene- $\mathrm{d}_{10}$, chrysene- $\mathrm{d}_{12}$, and perylene- $\mathrm{d}_{12}$. 

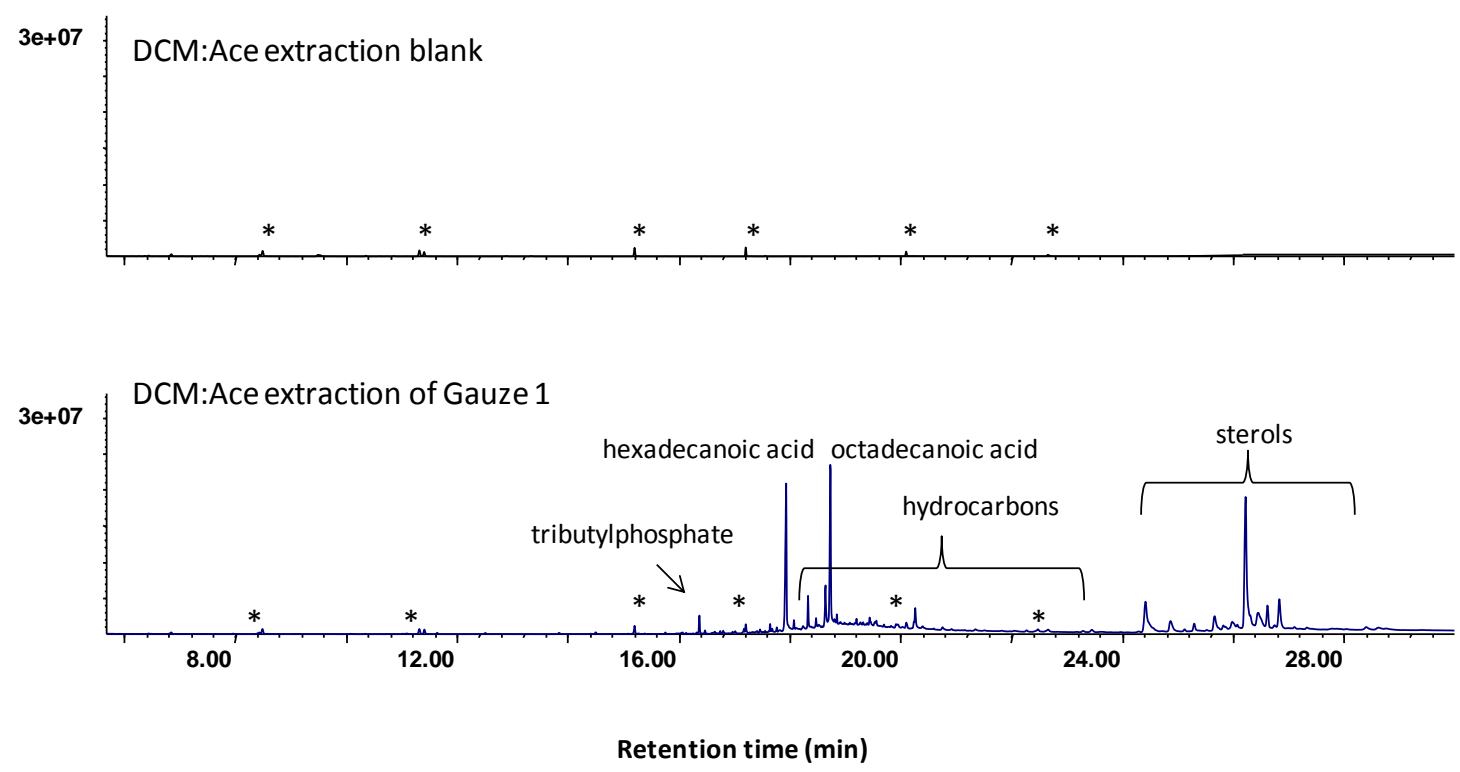

Figure A-5. Total ion chromatogram produced when a Gauze 1 was extracted with $50 / 50(v / v)$ dichloromethane:acetone (DCM:Ace). Note that "**" indicate $1 \mu \mathrm{g}$ each of internal standards that were added to the final sample extract (volume of $1 \mathrm{~mL}$ ) prior to analysis. Internal standards, in order of increasing retention time were 1,4-dichlorobenzene- $\mathrm{d}_{4}$, naphthalene- $\mathrm{d}_{8}$, acenaphthene- $\mathrm{d}_{10}$, phenanthrene$\mathrm{d}_{10}$, chrysene- $\mathrm{d}_{12}$, and perylene- $\mathrm{d}_{12}$. 

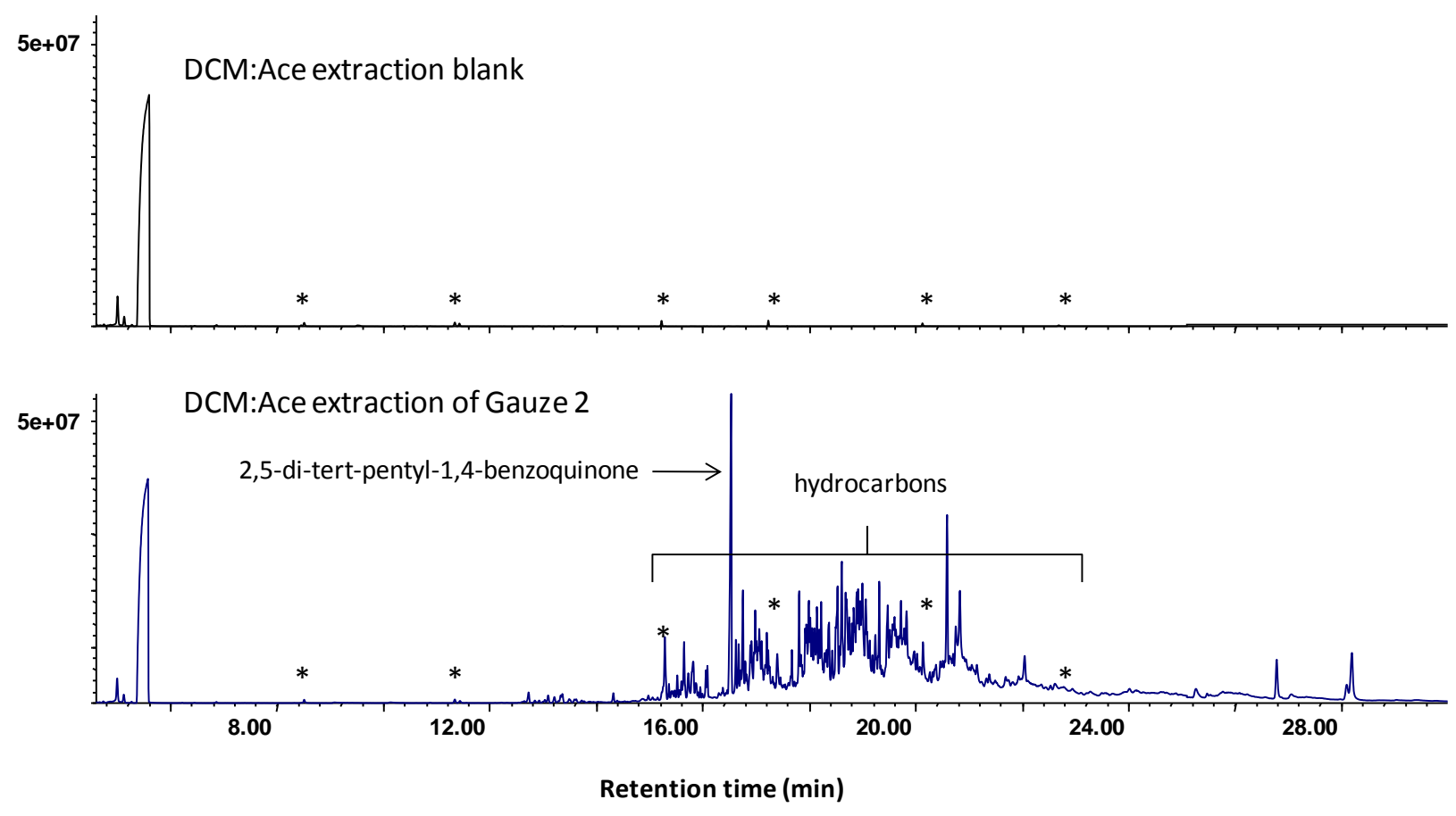

Figure A-6. Total ion chromatogram produced when a Gauze 2 was extracted with 50/50 (v/v) dichloromethane:acetone (DCM:Ace). Note that “*” indicate $1 \mu \mathrm{g}$ each of internal standards that were added to the final sample extract (volume of $1 \mathrm{~mL}$ ) prior to analysis. Internal standards, in order of increasing retention time were 1,4-dichlorobenzene- $\mathrm{d}_{4}$, naphthalene- $\mathrm{d}_{8}$, acenaphthene- $\mathrm{d}_{10}$, phenanthrene$\mathrm{d}_{10}$, chrysene- $\mathrm{d}_{12}$, and perylene- $\mathrm{d}_{12}$. 

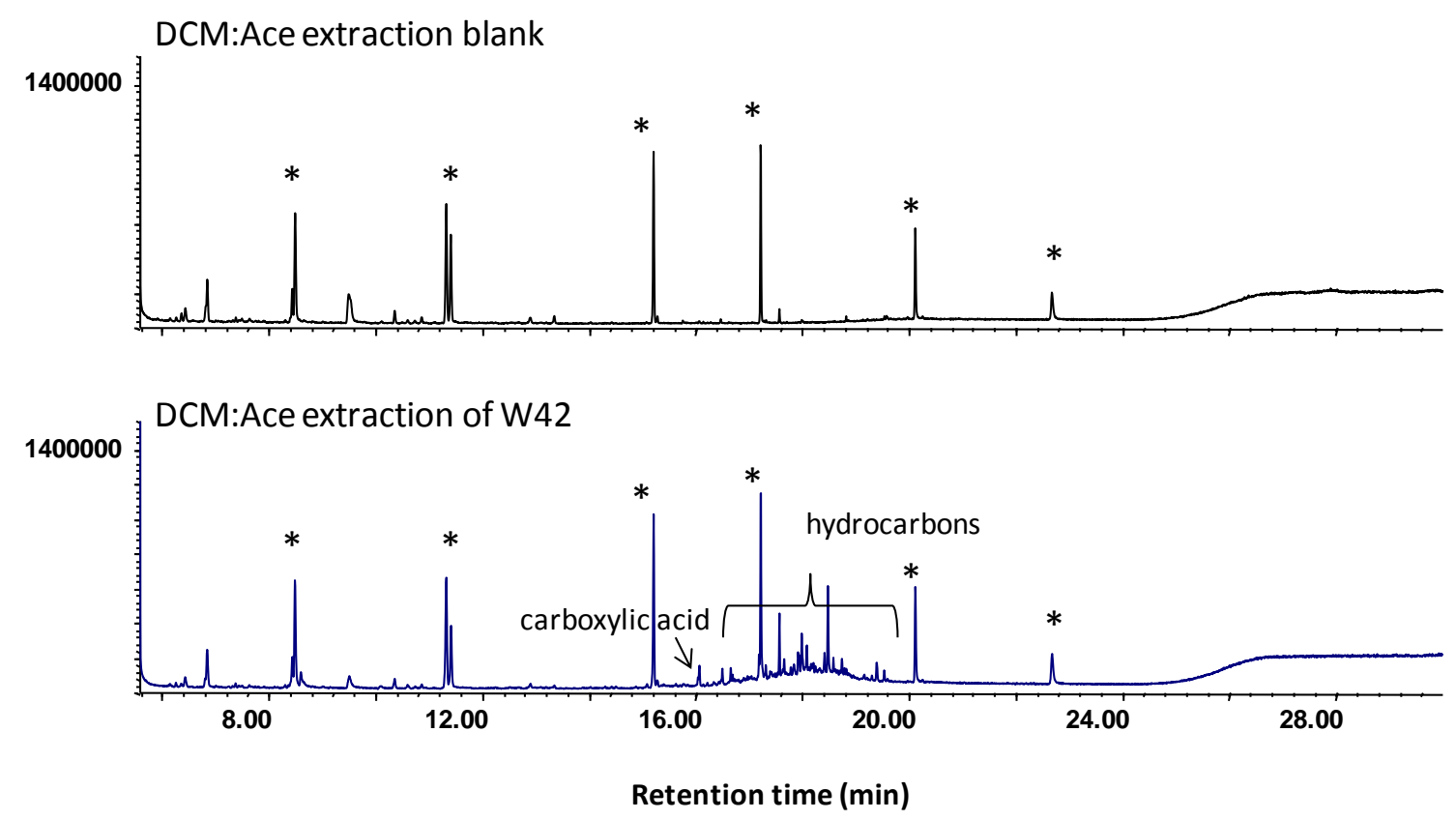

Figure A-7. Total ion chromatogram produced when a Whatman 42 filter (W42) was extracted with 50/50 (v/v) dichloromethane:acetone (DCM:Ace). Note that "*” indicate $1 \mu \mathrm{g}$ each of internal standards that were added to the final sample extract (volume of $1 \mathrm{~mL}$ ) prior to analysis. Internal standards, in order of increasing retention time were 1,4-dichlorobenzene- $\mathrm{d}_{4}$, naphthalene- $\mathrm{d}_{8}$, acenaphthene- $\mathrm{d}_{10}$, phenanthrene- $\mathrm{d}_{10}$, chrysene- $\mathrm{d}_{12}$, and perylene- $\mathrm{d}_{12}$. 

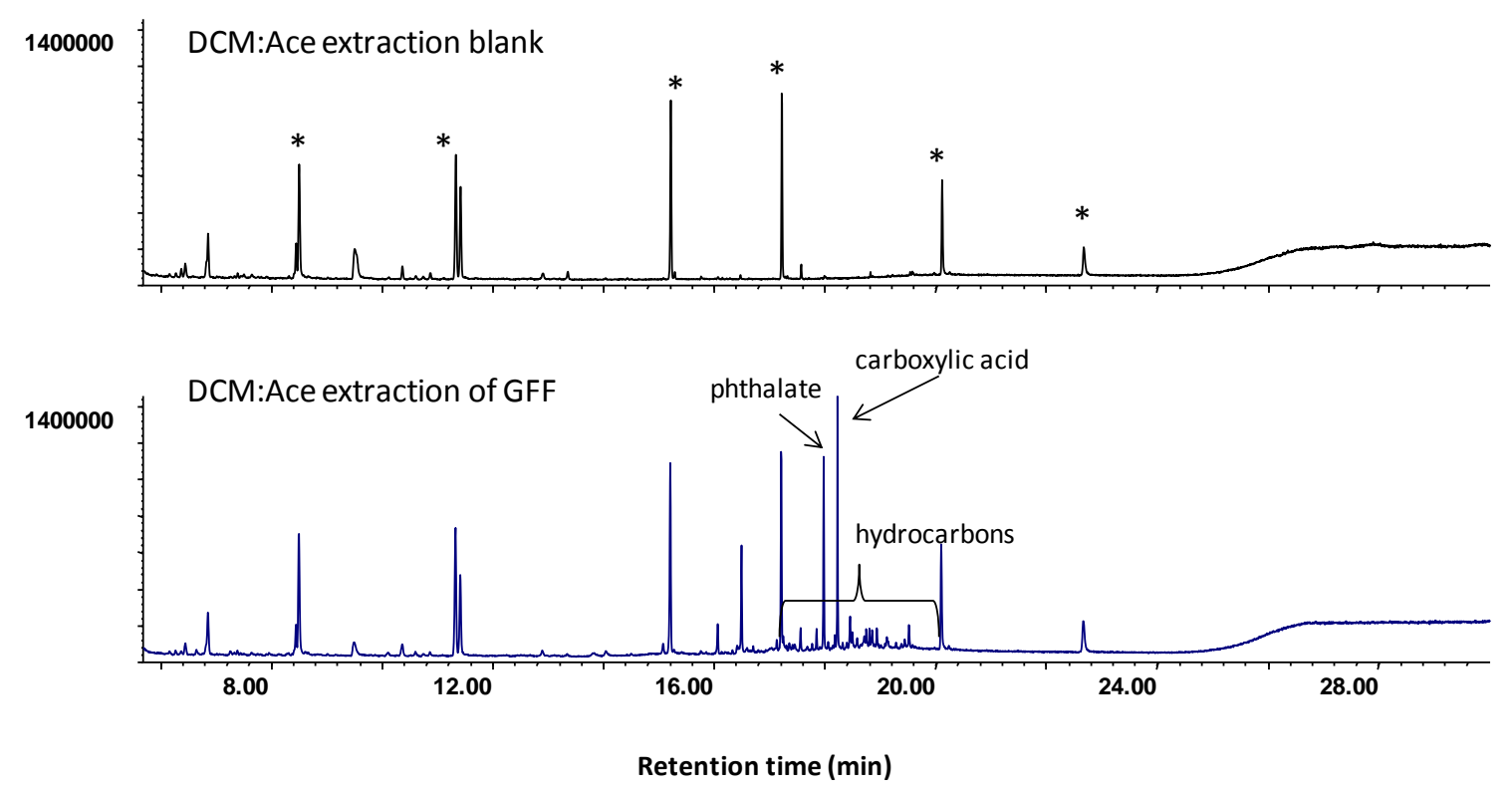

Figure A-8. Total ion chromatogram produced when a glass fiber filter (GFF) was extracted with 50/50 $(\mathrm{v} / \mathrm{v})$ dichloromethane:acetone (DCM:Ace). Note that “*” indicate $1 \mu \mathrm{g}$ each of internal standards that were added to the final sample extract (volume of $1 \mathrm{~mL}$ ) prior to analysis. Internal standards, in order of increasing retention time were 1,4 -dichlorobenzene- $\mathrm{d}_{4}$, naphthalene- $\mathrm{d}_{8}$, acenaphthene- $\mathrm{d}_{10}$, phenanthrene$\mathrm{d}_{10}$, chrysene- $\mathrm{d}_{12}$, and perylene- $\mathrm{d}_{12}$. 

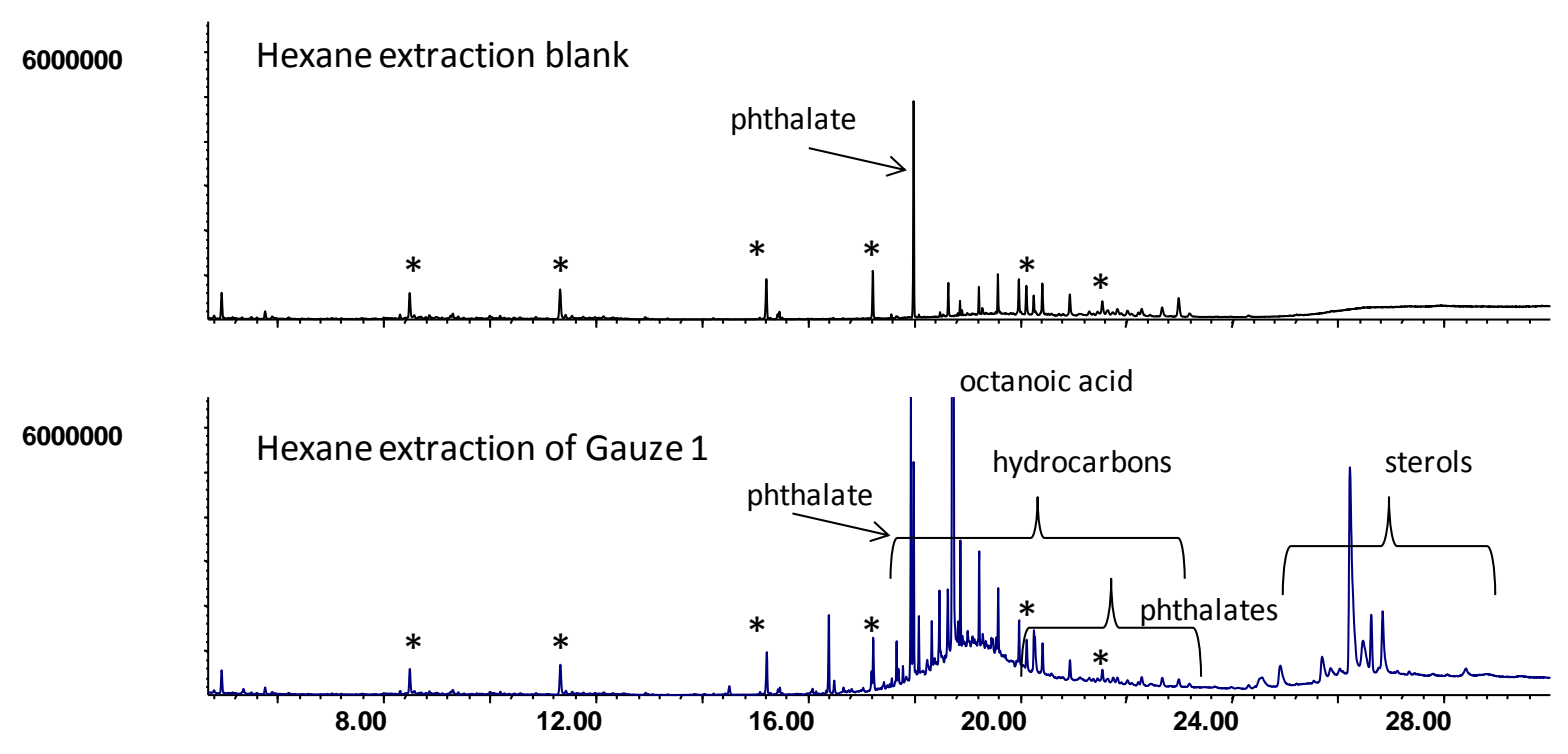

Retention time (min)

Figure A-9. Total ion chromatogram produced when Gauze 1 was extracted with hexane. Note that "**" indicate $1 \mu \mathrm{g}$ each of internal standards that were added to the final sample extract (volume of $1 \mathrm{~mL}$ ) prior to analysis. Internal standards, in order of increasing retention time were 1,4-dichlorobenzene- $\mathrm{d}_{4}$, naphthalene- $\mathrm{d}_{8}$, acenaphthene- $\mathrm{d}_{10}$, phenanthrene- $\mathrm{d}_{10}$, chrysene- $\mathrm{d}_{12}$, and perylene- $\mathrm{d}_{12}$. 

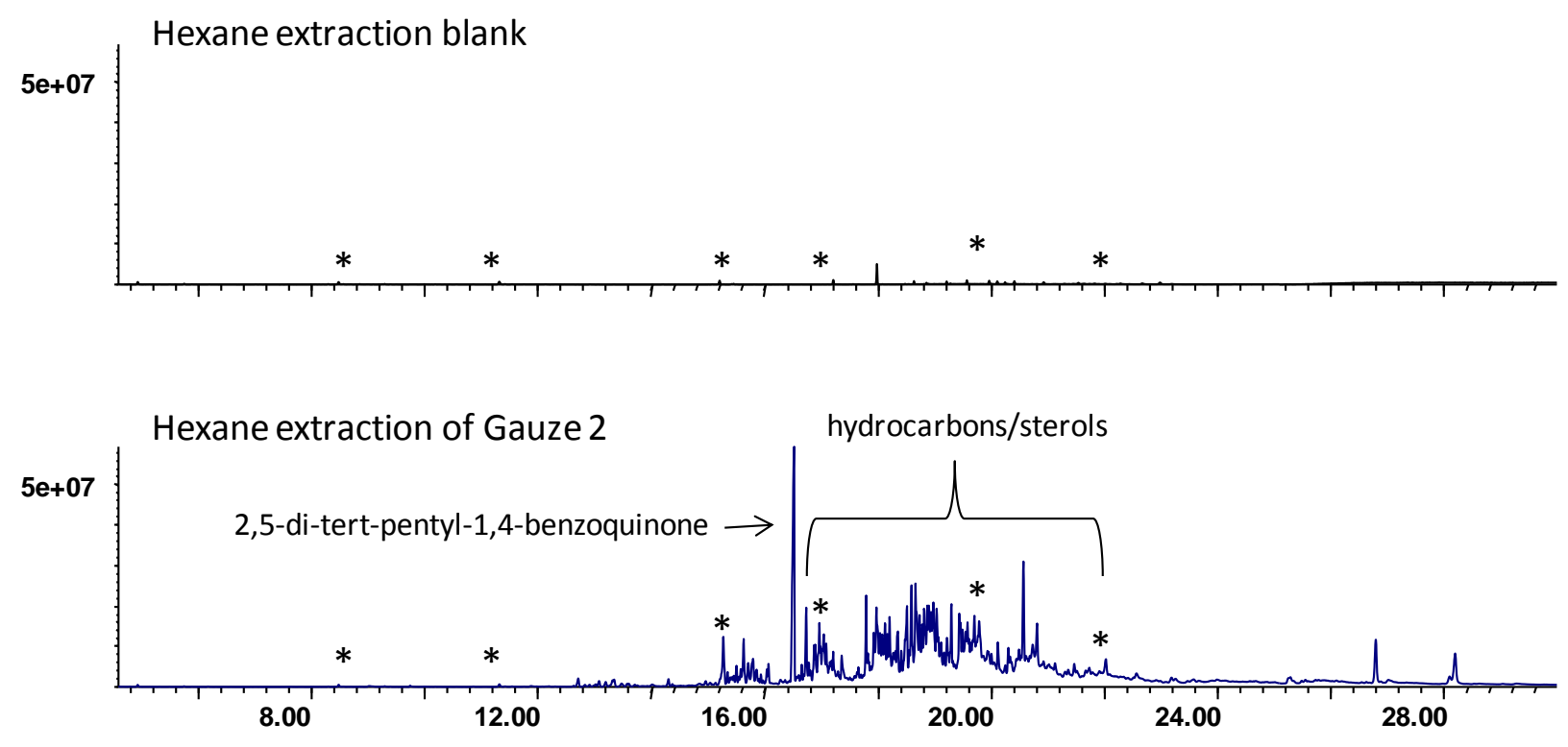

Retention time (min)

Figure A-10. Total ion chromatogram produced when Gauze 2 was extracted with hexane. Note that "*” indicate $1 \mu \mathrm{g}$ each of internal standards that were added to the final sample extract (volume of $1 \mathrm{~mL}$ ) prior to analysis. Internal standards, in order of increasing retention time were 1,4-dichlorobenzene- $\mathrm{d}_{4}$, naphthalene- $\mathrm{d}_{8}$, acenaphthene- $\mathrm{d}_{10}$, phenanthrene- $\mathrm{d}_{10}$, chrysene- $\mathrm{d}_{12}$, and perylene- $\mathrm{d}_{12}$. 

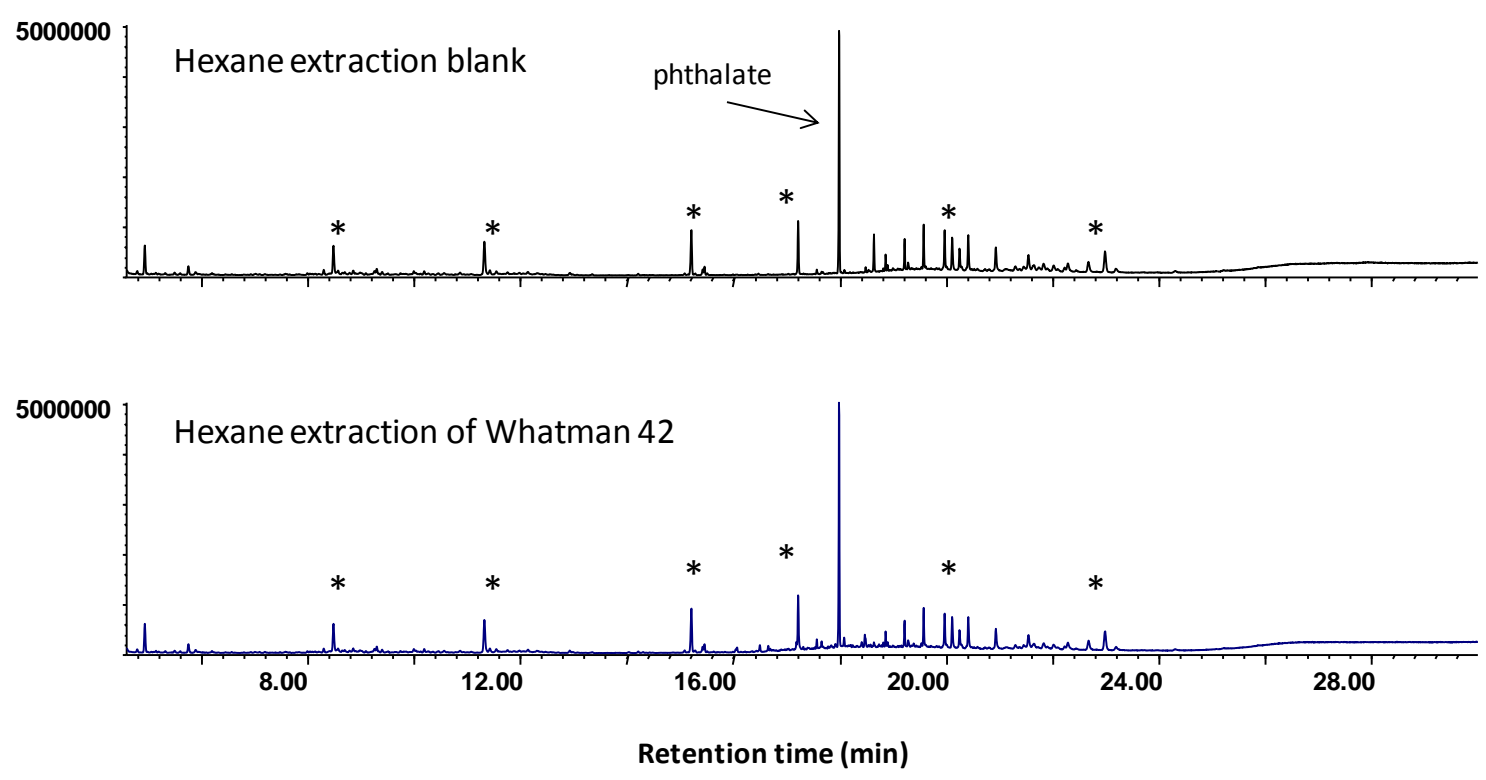

Figure A-11. Total ion chromatogram produced when Whatman 42 filter paper was extracted with hexane. Note that "*" indicate $1 \mu \mathrm{g}$ each of internal standards that were added to the final sample extract (volume of $1 \mathrm{~mL}$ ) prior to analysis. Internal standards, in order of increasing retention time were 1,4dichlorobenzene- $\mathrm{d}_{4}$, naphthalene- $\mathrm{d}_{8}$, acenaphthene- $\mathrm{d}_{10}$, phenanthrene- $\mathrm{d}_{10}$, chrysene- $\mathrm{d}_{12}$, and perylene- $\mathrm{d}_{12}$. 

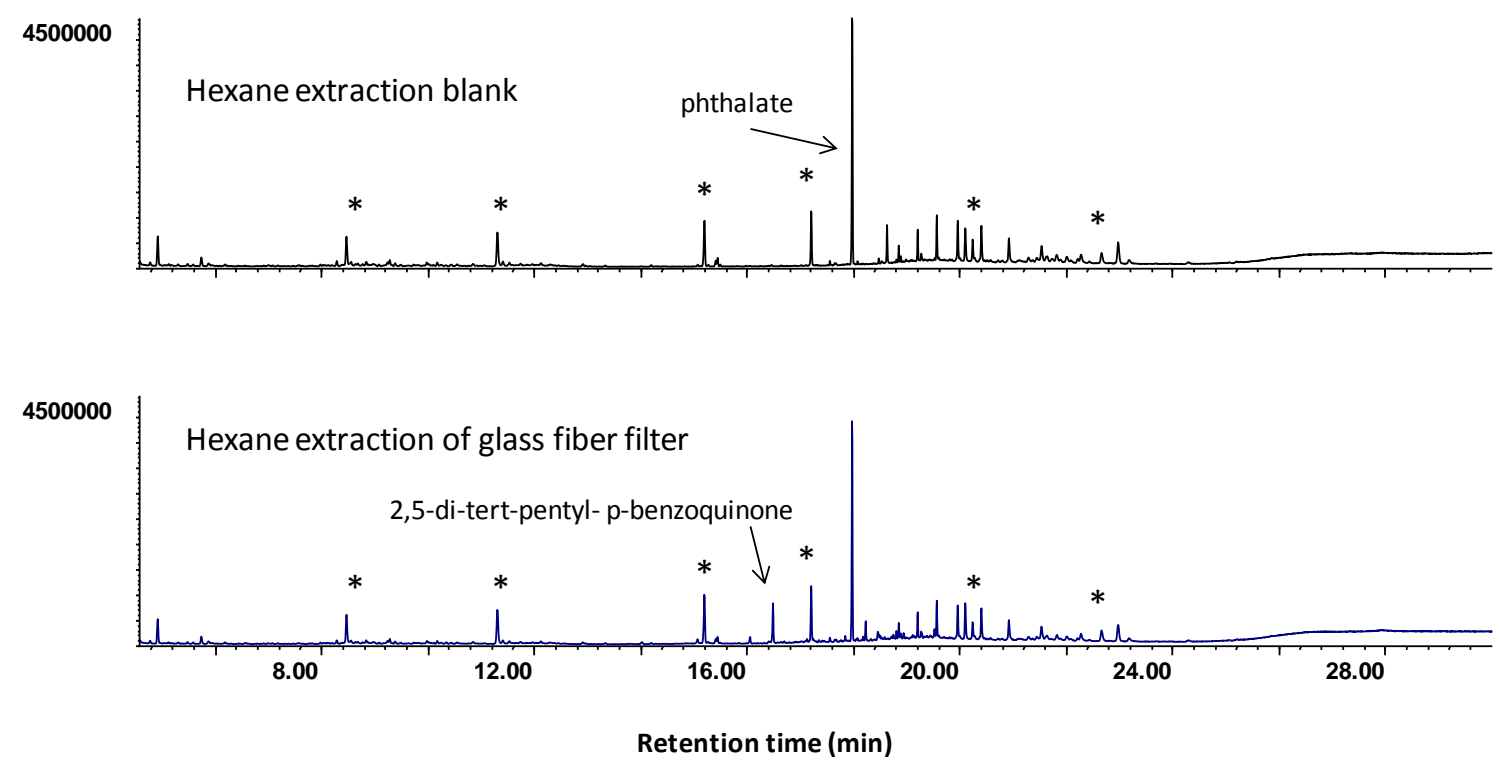

Figure A-12. Total ion chromatogram produced when a glass fiber filter was extracted with hexane. Note that "*" indicate $1 \mu \mathrm{g}$ each of internal standards that were added to the final sample extract (volume of $1 \mathrm{~mL}$ ) prior to analysis. Internal standards, in order of increasing retention time were 1,4dichlorobenzene- $\mathrm{d}_{4}$, naphthalene- $\mathrm{d}_{8}$, acenaphthene- $\mathrm{d}_{10}$, phenanthrene- $\mathrm{d}_{10}$, chrysene- $\mathrm{d}_{12}$, and perylene- $\mathrm{d}_{12}$. 
IPA extraction blank

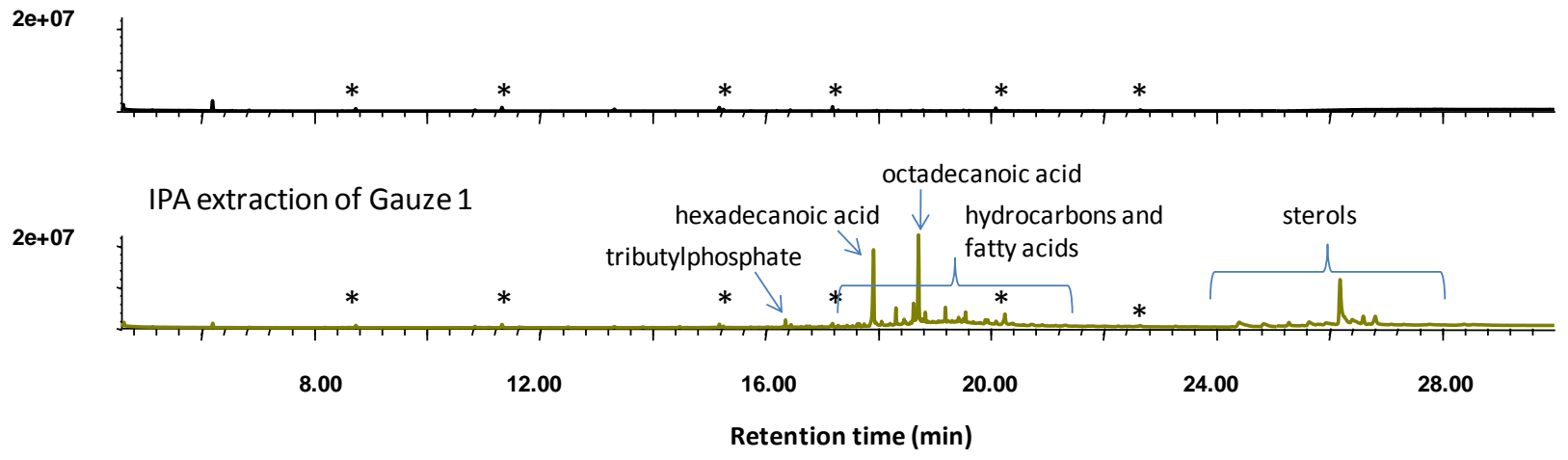

Figure A-13. Total ion chromatogram produced when Gauze 1 was extracted with isopropanol (IPA). Note that "*" indicate $1 \mu \mathrm{g}$ each of internal standards that were added to the final sample extract (volume of $1 \mathrm{~mL}$ ) prior to analysis. Internal standards, in order of increasing retention time were 1,4dichlorobenzene- $\mathrm{d}_{4}$, naphthalene- $\mathrm{d}_{8}$, acenaphthene- $\mathrm{d}_{10}$, phenanthrene- $\mathrm{d}_{10}$, chrysene- $\mathrm{d}_{12}$, and perylene- $\mathrm{d}_{12}$. 

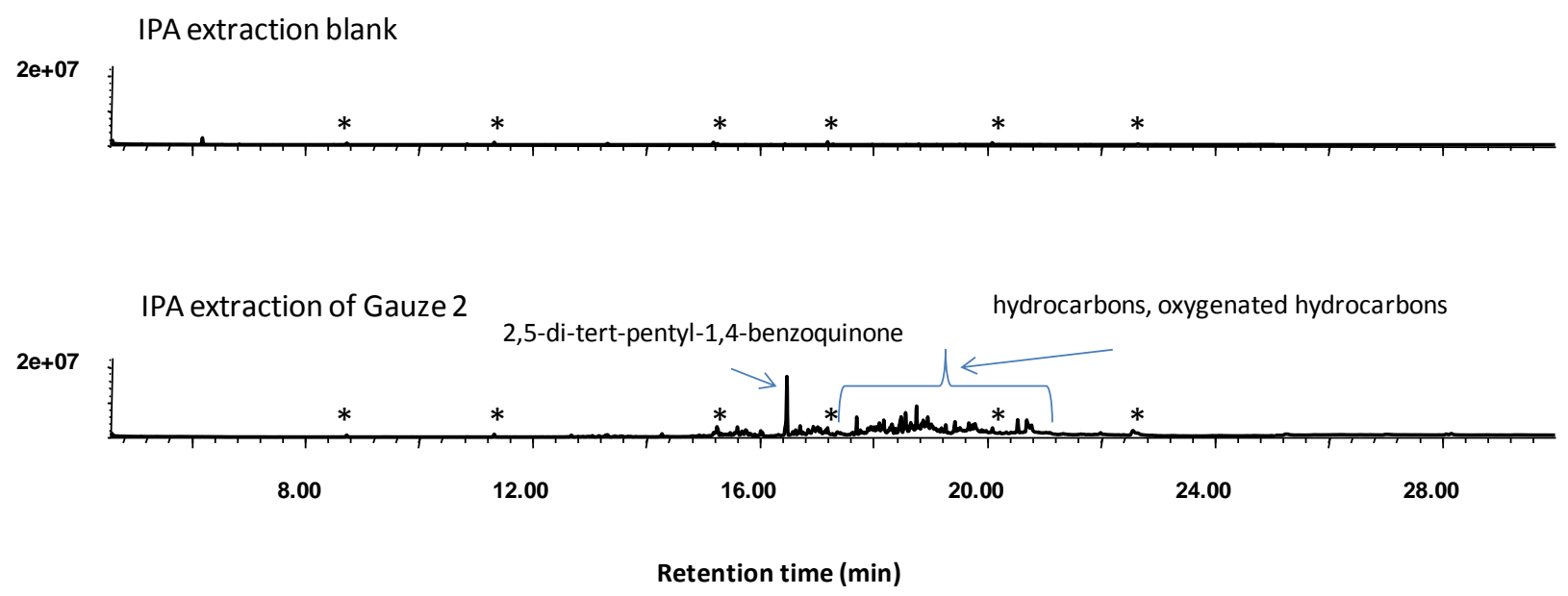

Figure A-14. Total ion chromatogram produced when Gauze 2 was extracted with isopropanol (IPA). Note that "*" indicate $1 \mu \mathrm{g}$ each of internal standards that were added to the final sample extract (volume of $1 \mathrm{~mL}$ ) prior to analysis. Internal standards, in order of increasing retention time were 1,4dichlorobenzene- $\mathrm{d}_{4}$, naphthalene- $\mathrm{d}_{8}$, acenaphthene- $\mathrm{d}_{10}$, phenanthrene- $\mathrm{d}_{10}$, chrysene- $\mathrm{d}_{12}$, and perylene- $\mathrm{d}_{12}$. 

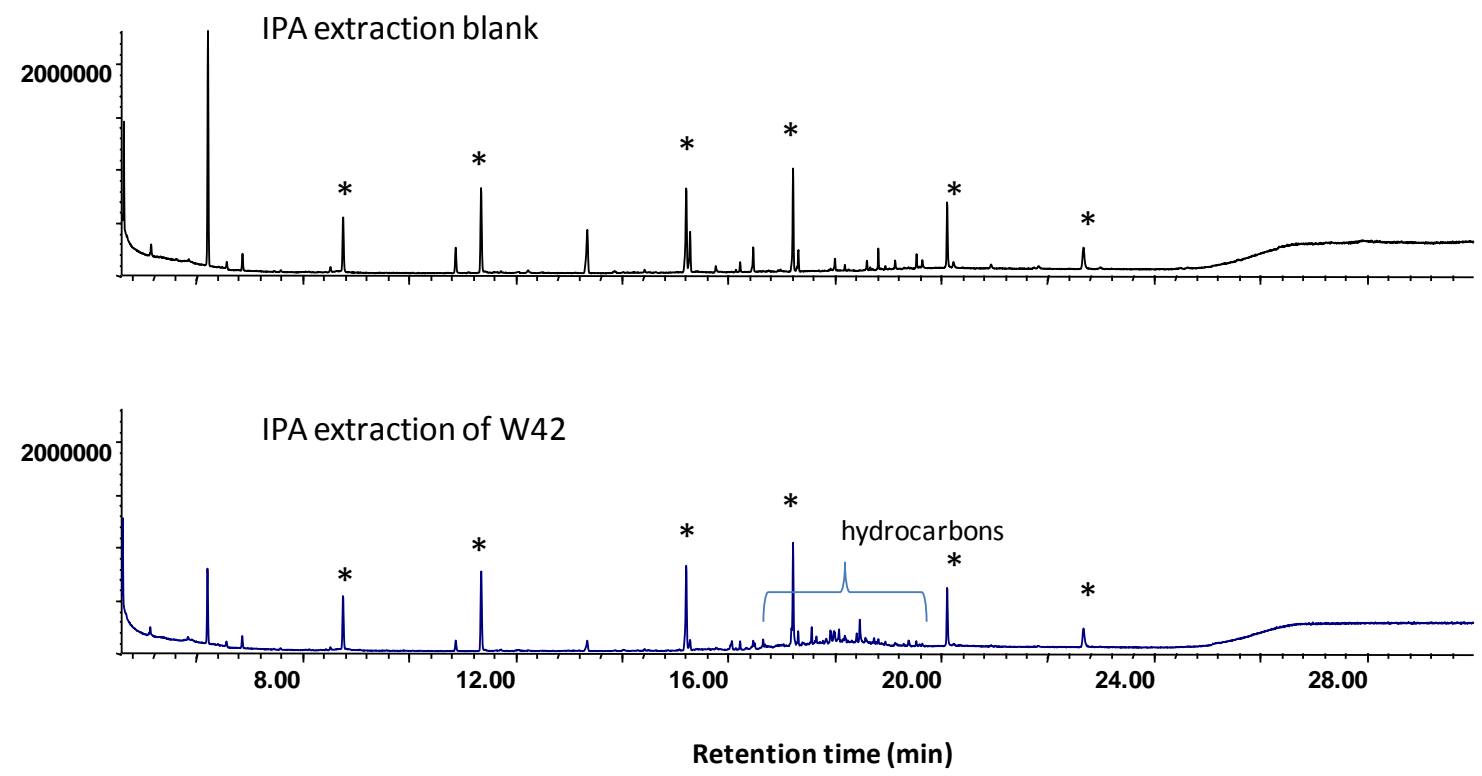

Figure A-15. Total ion chromatogram produced when Whatman 42 filter (W42) was extracted with isopropanol (IPA). Note that "*" indicate $1 \mu \mathrm{g}$ each of internal standards that were added to the final sample extract (volume of $1 \mathrm{~mL}$ ) prior to analysis. Internal standards, in order of increasing retention time were 1,4-dichlorobenzene- $\mathrm{d}_{4}$, naphthalene- $\mathrm{d}_{8}$, acenaphthene- $\mathrm{d}_{10}$, phenanthrene- $\mathrm{d}_{10}$, chrysene- $\mathrm{d}_{12}$, and perylene- $\mathrm{d}_{12}$. 


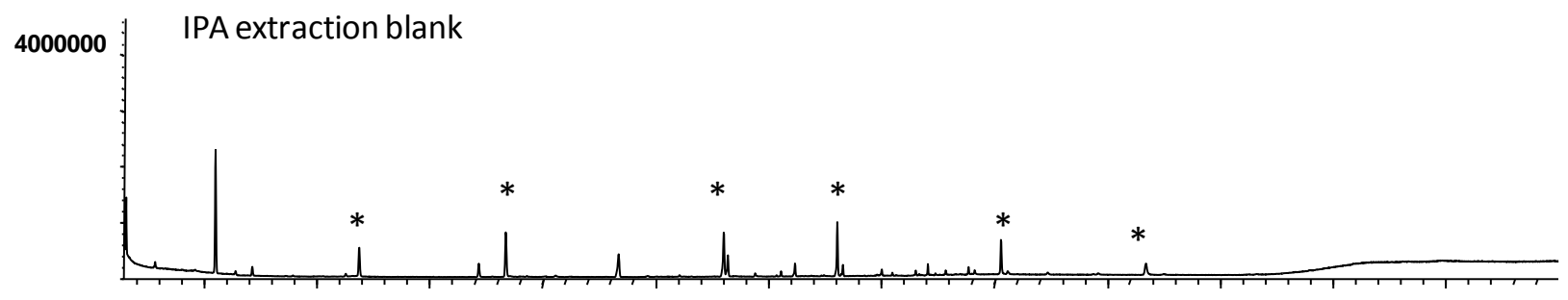

cyclic carboxylic acid

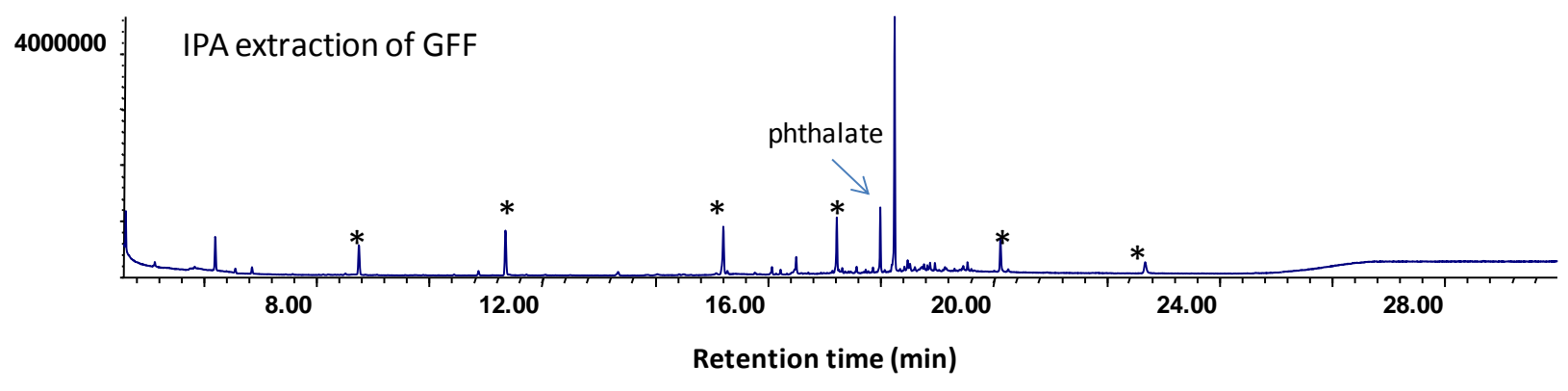

Figure A-16. Total ion chromatogram produced when glass fiber filter (GFF) was extracted with isopropanol (IPA). Note that "*" indicate $1 \mu \mathrm{g}$ each of internal standards that were added to the final sample extract (volume of $1 \mathrm{~mL}$ ) prior to analysis. Internal standards, in order of increasing retention time were 1,4-dichlorobenzene- $\mathrm{d}_{4}$, naphthalene- $\mathrm{d}_{8}$, acenaphthene- $\mathrm{d}_{10}$, phenanthrene- $\mathrm{d}_{10}$, chrysene- $\mathrm{d}_{12}$, and perylene- $\mathrm{d}_{12}$. 

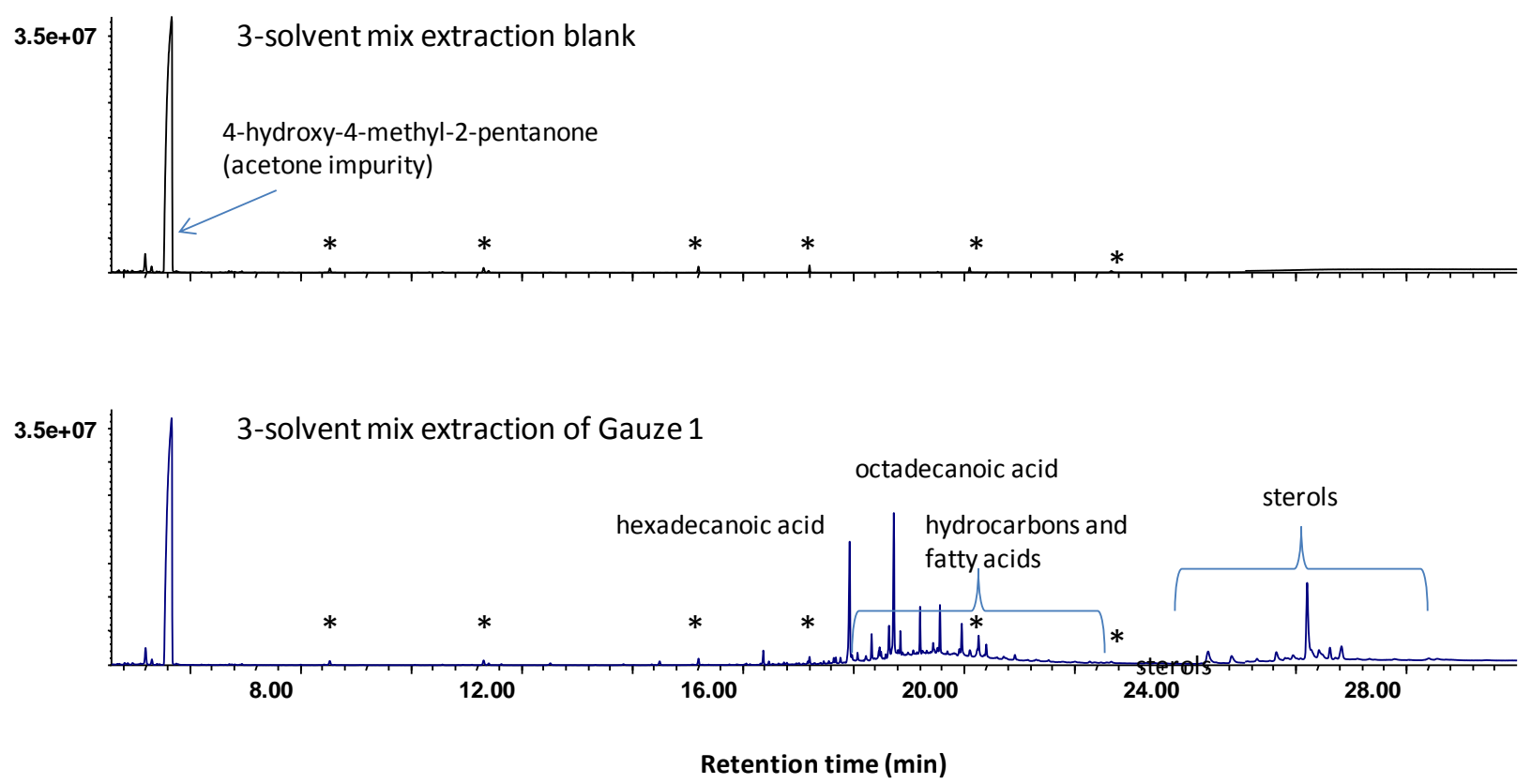

Figure A-17. Total ion chromatogram produced when Gauze 1 was extracted with the three-solvent mix of $25 / 50 / 25(\mathrm{v} / \mathrm{v} / \mathrm{v})$ acetone/dichloromethane/ethyl acetate. Note that "**" indicate $1 \mu \mathrm{g}$ each of internal standards that were added to the final sample extract (volume of $1 \mathrm{~mL}$ ) prior to analysis. Internal standards, in order of increasing retention time were 1,4-dichlorobenzene- $\mathrm{d}_{4}$, naphthalene- $\mathrm{d}_{8}$, acenaphthene- $\mathrm{d}_{10}$, phenanthrene- $\mathrm{d}_{10}$, chrysene- $\mathrm{d}_{12}$, and perylene- $\mathrm{d}_{12}$. 


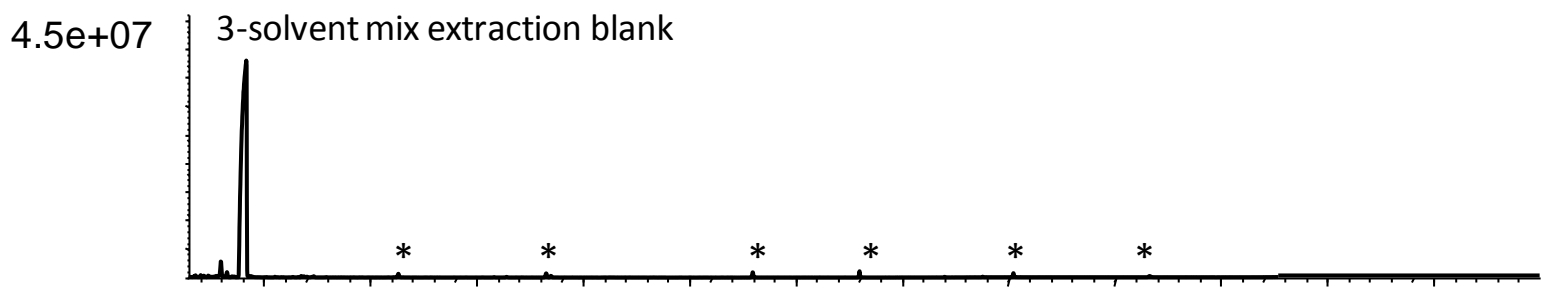

3-solvent mix extraction of Gauze 2

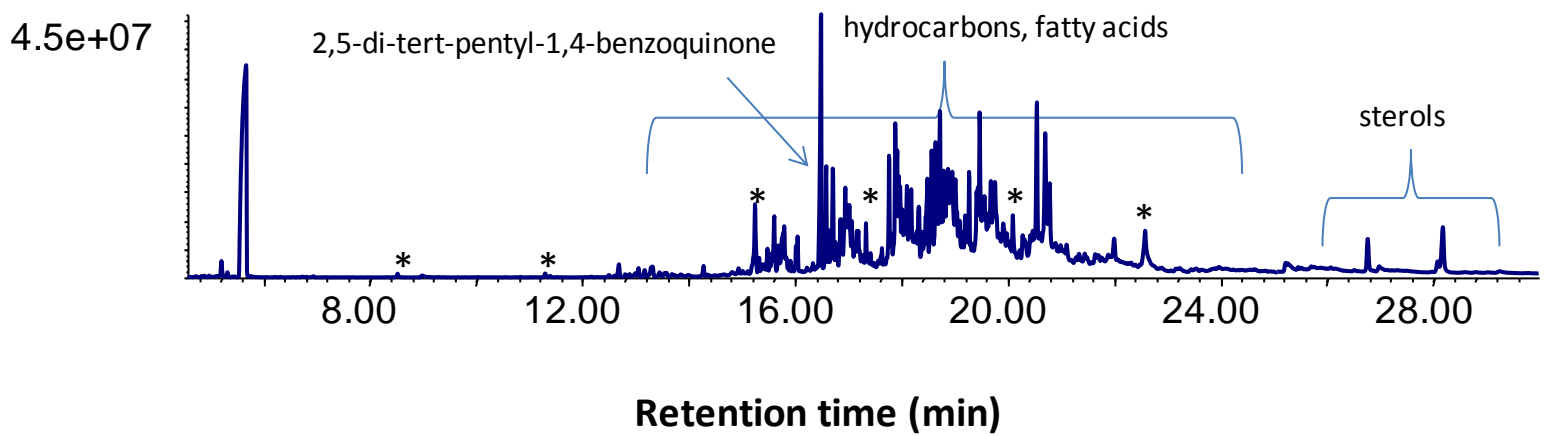

Figure A-18. Total ion chromatogram produced when Gauze 2 was extracted with the three-solvent mix of 25/50/25 (v/v/v) acetone/dichloromethane/ethyl acetate. Note that "**" indicate $1 \mu \mathrm{g}$ each of internal standards that were added to the final sample extract (volume of $1 \mathrm{~mL}$ ) prior to analysis. Internal standards, in order of increasing retention time were 1,4-dichlorobenzene- $\mathrm{d}_{4}$, naphthalene- $\mathrm{d}_{8}$, acenaphthene- $d_{10}$, phenanthrene- $d_{10}$, chrysene- $d_{12}$, and perylene- $d_{12}$. 

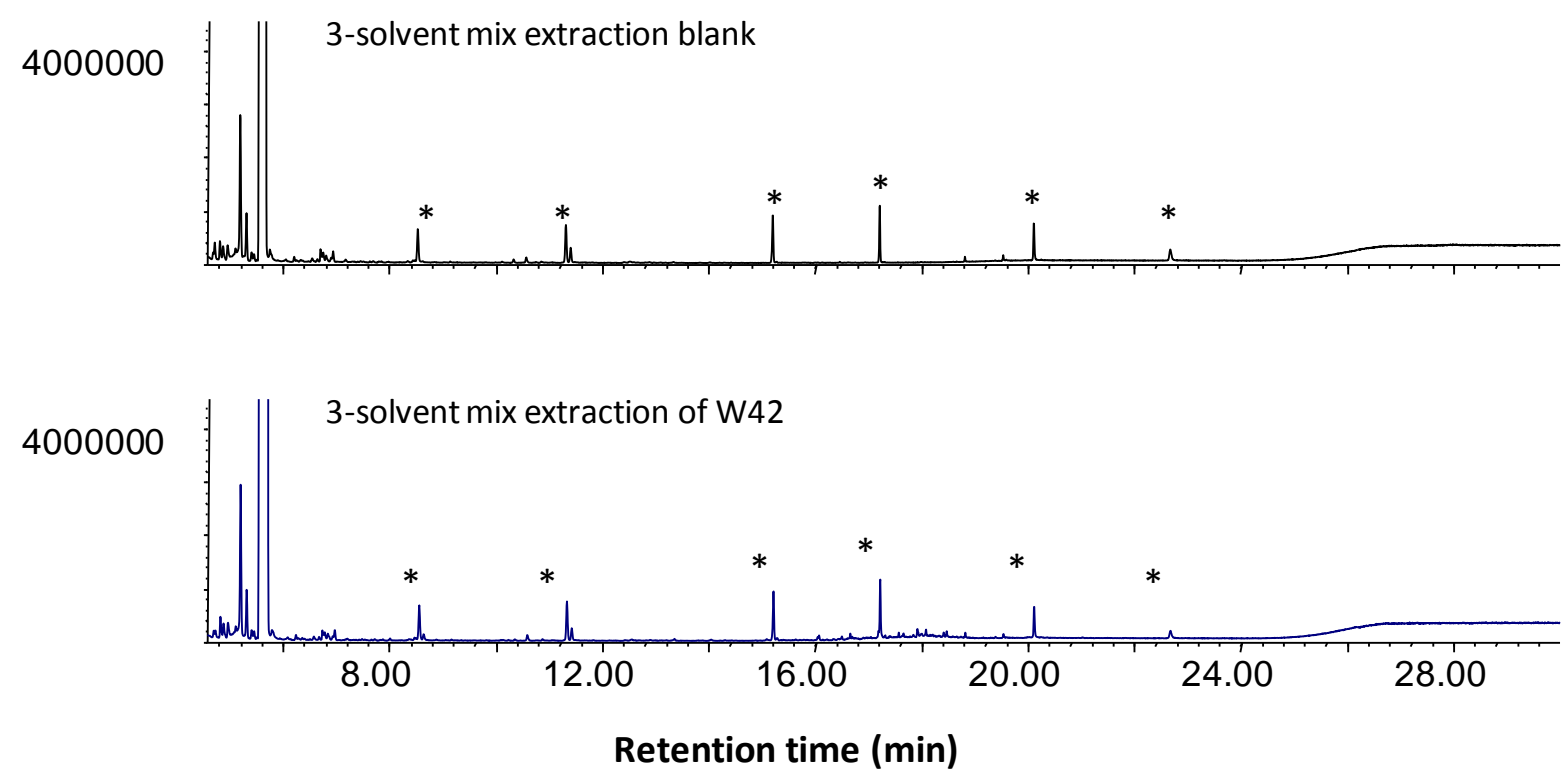

Figure A-19. Total ion chromatogram produced when Whatman 42 filter paper was extracted with the three-solvent mix of 25/50/25 (v/v/v) acetone/dichloromethane/ethyl acetate. Note that "*" indicate $1 \mu \mathrm{g}$ each of internal standards that were added to the final sample extract (volume of $1 \mathrm{~mL}$ ) prior to analysis. Internal standards, in order of increasing retention time were 1,4-dichlorobenzene- $\mathrm{d}_{4}$, naphthalene- $\mathrm{d}_{8}$, acenaphthene- $\mathrm{d}_{10}$, phenanthrene- $\mathrm{d}_{10}$, chrysene- $\mathrm{d}_{12}$, and perylene- $\mathrm{d}_{12}$. 

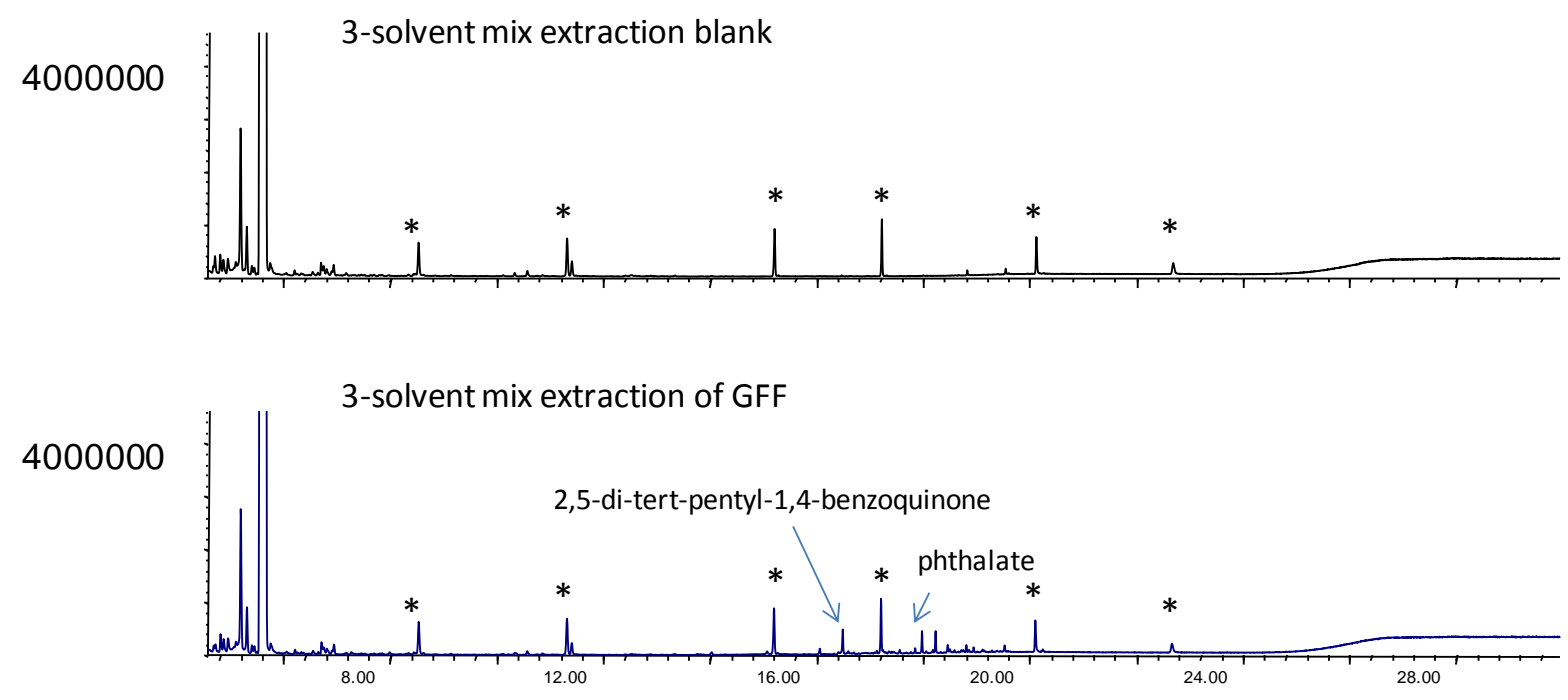

\section{Retention time (min)}

Figure A-20. Total ion chromatogram produced when a glass fiber filter was extracted with the threesolvent mix of 25/50/25 (v/v/v) acetone/dichloromethane/ethyl acetate. Note that "**" indicate $1 \mu \mathrm{g}$ each of internal standards that were added to the final sample extract (volume of $1 \mathrm{~mL}$ ) prior to analysis. Internal standards, in order of increasing retention time were 1,4-dichlorobenzene- $\mathrm{d}_{4}$, naphthalene- $\mathrm{d}_{8}$, acenaphthene- $\mathrm{d}_{10}$, phenanthrene- $\mathrm{d}_{10}$, chrysene- $\mathrm{d}_{12}$, and perylene- $\mathrm{d}_{12}$. 